NBER WORKING PAPER SERIES

\title{
PRECISE OR IMPRECISE PROBABILITIES? EVIDENCE FROM SURVEY RESPONSE ON LATE-ONSET DEMENTIA
}

\author{
Pamela Giustinelli \\ Charles F. Manski \\ Francesca Molinari \\ Working Paper 26125 \\ http://www.nber.org/papers/w26125 \\ NATIONAL BUREAU OF ECONOMIC RESEARCH \\ 1050 Massachusetts Avenue \\ Cambridge, MA 02138 \\ July 2019
}

\begin{abstract}
We thank Mostafa Goudarzi and Adam Karabatakis for able research assistance. Giustinelli gratefully acknowledges support from the National Institute on Aging (NIA P01-AG10179 and P30-AG012846), the National Science Foundation (SES1131500) for the University of Michigan node of the NSF-Census Research Network (NCRN), and the Michigan Institute for Teaching and Research in Economics (MITRE)'s Undergraduate Student Support program. Part of this research was carried out while Molinari was on sabbatical leave at the Department of Economics at Duke University, whose hospitality she gratefully acknowledges. We have received useful feedback from Diego Ufbal, James Banks, seminar participants at Bocconi and IFS (UCL), as well as participants in the 2019 University of Michigan Conference on Health and Retirement: Expectations, Cognition and Behavior and the 2019 Conference on Advances in Decision Analysis. The views expressed herein are those of the authors and do not necessarily reflect the views of the National Bureau of Economic Research.
\end{abstract}

NBER working papers are circulated for discussion and comment purposes. They have not been peer-reviewed or been subject to the review by the NBER Board of Directors that accompanies official NBER publications.

(C) 2019 by Pamela Giustinelli, Charles F. Manski, and Francesca Molinari. All rights reserved. Short sections of text, not to exceed two paragraphs, may be quoted without explicit permission provided that full credit, including $(\odot$ notice, is given to the source. 
Precise or Imprecise Probabilities? Evidence from Survey Response on Late-onset Dementia Pamela Giustinelli, Charles F. Manski, and Francesca Molinari

NBER Working Paper No. 26125

July 2019

JEL No. D80,D84,I0

\begin{abstract} insurance purchase decisions.

Pamela Giustinelli

Department of Economics

Bocconi University

Milan, Italy

pamela.giustinelli@gmail.com

Charles F. Manski

Department of Economics

Northwestern University

2211 Campus Drive

Evanston, IL 60208-2600

and NBER

cfmanski@northwestern.edu

\author{
Francesca Molinari \\ Department of Economics \\ Cornell University \\ Ithaca, NY \\ fm72@cornell.edu
}

We elicit numerical expectations for late-onset dementia in the Health and Retirement Study. Our elicitation distinguishes between precise and imprecise probabilities, while accounting for rounding of reports. Respondents quantify imprecision using probability intervals. Nearly half of respondents hold imprecise dementia probabilities, while almost a third of precise-probability respondents round their reports. We provide the first empirical evidence on dementia-risk perceptions among dementia-free older Americans and novel evidence about imprecise probabilities in a nationally-representative sample. We show, in a specific framework, that failing to account for imprecise or rounded probabilities can yield incorrect predictions of long-term care 


\section{Introduction}

When considering expectations for uncertain events, most economic research maintains that agents hold precise subjective probabilities. Yet economists and others have long been concerned that this may not be the case (e.g., Keynes, 1921; Knight, 1921; Ellsberg, 1961), especially when available information is limited.

This concern has stimulated much research on imprecise probabilities, also known as deep uncertainty or ambiguity; e.g., see reviews by Walley (1991), Camerer and Weber (1992), and Gilboa and Marinacci (2013). However, the existing research is largely theoretical or experimental. Nearly nothing is known about the precision of the probabilistic expectations people hold in real life when planning or making decisions with uncertain consequences and limited knowledge.

To learn empirically about the extent of precision in probabilistic expectations, we elicited subjective probabilities of developing late-onset dementia and potentially related long-term care (LTC) decisions, purchasing LTC insurance or entering a nursing home, among currently dementia-free respondents in the U.S. Health and Retirement Study (HRS). We devised an elicitation procedure to distinguish between respondents holding precise probabilities and ones holding imprecise probabilities, while also accounting for rounding or approximation of probability reports. Respondents with imprecise probabilities were asked to quantify imprecision by means of probability intervals.

We find that nearly half of respondents hold imprecise probabilities of developing late-onset dementia and, across all LTC and dementia outcomes, over $60 \%$ of respondents expresses imprecision at least once. We compare respondents' perceptions of dementia risk with existing estimates of lifetime risk from the medical literature and find that the two sets of estimates align reasonably well on average.

To the best of our knowledge, this paper provides the first empirical evidence about perceptions of late-onset dementia risk among currently dementia-free older Americans as well as new empirical evidence about imprecision of probabilistic expectations in a nationally representative sample. Using a specific framework of LTC insurance purchase with uncertain dementia state, we show that failing to distinguish between agents with precise vs. imprecise dementia probabilities, or to account for rounding of probability reports among respondents with precise dementia probabilities, may yield incorrect predictions of demand for LTC insurance for common response configurations in our data. 
Since its start in 1992, the HRS has been at the forefront of measurement of economic expectations of older U.S. households in multiple domains of personal and macroeconomic uncertainty, using a numerical scale of percent chance (e.g., Manski, 2004; Hurd, 2009). The standard HRS question format, and that of other data sources, asks respondents to report precise probabilities as single numbers between 0 and 100 percent. These data have generally been used at face value in the empirical literature, implicitly or explicitly modeling agents as holding precise probabilities. However, we know from past work that people may be willing and able to respond in multiple ways, reporting probabilities on verbal and numerical scales as well as on scales of differing granularities (e.g., Olson and Budescu, 1997; Woloshin et al., 2000; Manski and Molinari, 2010). Thus, we think it important to understand the nature of people’s beliefs underlying what they report.

To this end, we developed an elicitation procedure that starts from the precise percent-chance format with which HRS respondents are already familiar and then uses two probing questions to learn about the nature of people's reports. The first probe asks whether the reported probability was intended to be an exact number or was rounded/approximated. When the response is rounded/approximated, a second probe permits the respondent to give an exact precise probability or an imprecise probability, stated as a range.

Our procedure builds on what has been learned in previous studies that explore modifications of the usual percent-chance question format to enable survey respondents to convey imprecise probabilities. ${ }^{5}$ In particular, the question format we develop builds on that used in the exploratory study performed by Manski and Molinari (2010), who posed interval probability questions eliciting longevity expectations from respondents in the American Life Panel.

Here we report findings from an experimental module that we placed in the 2016 fielding of the HRS. Our new HRS module collects data on an important subject from a representative sample. We use the point-interval format to elicit respondents' expectations over their future development of dementia and long-term care (LTC) plans. This paper focuses on expectations of dementia, with analysis of responses to the LTC questions to be reported separately.

Dementia is a high-priority topic in the research and policy agendas on aging. Alzheimer disease and related dementias (ADRD) are a class of irreversible progressive brain diseases,

\footnotetext{
5 These include Manski and Molinari (2010), Giustinelli and Pavoni (2017), and Delavande, Ganguli, and Mendel
} (2018). Wallsten, Forsyth, and Budescu (1983) report on earlier measurements in psychology, focusing on experts. 
currently incurable, that affects millions of Americans every year. In 2018, 5 to 6 million Americans were estimated to live with ADRD, the large majority over 65 years old (Alzheimer's Association, 2018). ${ }^{6}$ ADRD is one of the top-10 causes of death in the United States. In 2017, it ranked $6^{\text {th }}$ overall, $5^{\text {th }}$ among the over 65 , and $3^{\text {rd }}$ among the over 85 (Heron, 2019). Furthermore, ADRD has been estimated to impose a high economic burden on households and government programs due to the associated need for prolonged specialized care by the sick (Hurd et al., 2013). Important economic decisions of older individuals can potentially be affected by their perceptions of dementia risk, including precautionary savings choices, the timing of retirement, and the purchase of long-term care insurance.

Producing reliable forecasts of the future prevalence of dementia has proved challenging, as forecasts are sensitive to the historical data and modelling assumptions used (Hudomiet, Hurd and Rohwedder, 2018). Nevertheless, most forecasts agree that the prevalence of the illness will grow with the increasing size and proportion of the U.S. population over 65, also due to improved rates of early detection, treatment, and prevention of major causes of death other than dementia. If this is correct, the already high demand for LTC services such as nursing homes will rise.

Current statistics indicate that over $40 \%$ of residents in long-term care facilities have Alzheimer's Disease and over 70\% have some cognitive condition (National Center for Health Statistics, 2013). Recent economic literature using the HRS has found a strong link between the decision to buy LTC insurance and people's subjective probabilities of moving to a nursing home (e.g., Finkelstein and McGarry (2006)). However, to the best of our knowledge, nothing is known about people's beliefs of developing dementia as they age, or about how these beliefs are related to LTC decisions and outcomes. This data gap motivated our choice of measuring respondents' subjective probabilities of developing dementia in the future.

When thinking about elicitation of perceptions for dementia risk, it is important to recognize that, in general, available research on the prevalence of dementia does not provide evidence on the risk that currently healthy persons will develop dementia at some future point in their lives. ${ }^{7}$

\footnotetext{
${ }^{6}$ Most ADRD cases (> 90-95\%) are of the late-onset type, occurring in older individuals (60 and over). Late-onset dementia should be distinguished from early-onset dementia, which occurs in younger individuals (between 30 and 60 ). Early-onset ADRD is completely genetically determined; whereas, late-onset ADRD has been associated with multiple risk factors, only some being genetic (e.g., Ertekin-Taner (2007), NIA (2015)). Having the genetic variant associated with an increased risk of late-onset dementia is neither necessary nor sufficient for onset. And while susceptibility testing exists, it is rarely performed, as it is considered not predictive at the individual level.

${ }^{7}$ Later we review a few existing studies on the lifetime risk of developing dementia for specific demographic groups and compare their estimates with the subjective probabilities that we elicit in our sample.
} 
Medical researchers have developed easily accessible online tools that predict the chance that persons with specified age and health attributes will develop cardiovascular disease, breast cancer, and some other serious illnesses. However, as far as we are aware, there currently exists no similar tool predicting personalized risk of dementia. ${ }^{8}$ Given the absence of objective personalized predictors of dementia risk, the prediction task may be difficult for lay people. Hence, when initiating this research, we thought it reasonable to conjecture that many persons may hold imprecise expectations of their dementia risk - and also of LTC outcomes, to the extent that these may depend on dementia expectations. For this reason, we decided to elicit expectations as both precise (point) probabilities and as imprecise (interval) probabilities.

Our finding that nearly $50 \%$ of respondents displays imprecise dementia probabilities, and over $60 \%$ expresses imprecision across LTC and dementia outcomes, supports our initial conjecture. We further document that the amount of imprecision is sizeable and heterogeneous across respondents; the distribution of interval width has a median of 20 points and a dispersion of 70 points as measured by the difference between the $9^{\text {th }}$ decile ( 80 percent) and $1^{\text {st }}$ decile (10 percent).

We also investigate the extent to which initial responses of 0,50 or 100 are associated with higher levels of imprecision, as posited by some of the literature on "focal responses" in subjective expectations. Interestingly, we find that it is not the case in our setting.

Additionally, we study whether, and if so how, the prevalence of different probabilistic response types and the amount of probability imprecision vary with observed respondent characteristics. We find that older respondents are more likely than younger ones to report rounded or approximated probabilities and to hold interval probabilities. On the other hand, more educated respondents are less likely to report a rounded or approximated probability, but more likely to hold imprecise probabilities. We find no significant association between probabilistic response type and gender, nor between probabilistic response type and measured cognitive ability.

Respondents' expectations for developing dementia are also quite heterogeneous in magnitude. We analyze how these vary across respondents' characteristics. We find that mean dementia expectations vary non-monotonically with age and tend to increase with education On average,

${ }^{8}$ In an interview reported in ScienceDaily on May 22, 2018, the Alzheimer's Association chief science officer, Maria Carillo, Ph.D., states: "Just as there are risk predictors for whether you might have a heart attack, it will be important in the future to measure the likelihood that someone will develop Alzheimer's disease. In the future, when treatments are available, this would be helpful, especially for people in the stages before the clinical symptoms appear. For example, those people with the highest 10-year risk of getting Alzheimer's dementia would be high priority to volunteer for clinical trials evaluating Alzheimer's medications or other therapies.” 
women report higher dementia risk, but the difference with men is small and statistically insignificant. Non-white respondents tend to report lower dementia risk.

For each outcome, our elicitation procedure generates two measures of subjective expectations among respondents who round or approximate their initial report: an initial (rounded) pointprobability and a post-probe response which may be an (unrounded) point-probability or an interval-probability. Taking advantage of this data structure, we compare the initial reports that are elicited through the standard HRS format with the reports obtained after our probing questions. When doing so, we view the initial response as a potentially error-ridden measure of the true subjective probability and the post-probe response as a more accurate measure of the truth. As traditional in the measurement error literature (e.g., errors in variables), we investigate how the mean of the error-ridden measure varies as a function of the underlying true probability.

We find that individuals holding precise probabilities have a tendency, when asked using the standard format, to over-report very small probabilities compared to their post-probing reports. They also tend to under-report large probabilities. A similar pattern is exhibited by respondents holding imprecise probabilities, compared with the lower bound of the interval that they report post probing, conditional on the width of the interval. Interestingly, a sizeable proportion of imprecise-probability respondents report an interval that does not include the initial point report. This pattern, combined with rounding of initial reports by precise-probability respondents, implies that use of initial point-reports for prediction of economic decisions that depend on dementia probabilities can lead to incorrect predictions.

In Section 2, we review the relevant literature and define the scope of our analysis. In Section 3 , we describe the survey design and data collection. In Sections 4 and 5, we present our empirical analysis of dementia expectations, with Section 4 studying the (im)precision of expectations and Section 5 reporting substantive findings on how respondents perceive dementia risk. In Section 6, we discuss implications of our findings for prediction and modelling. Section 7 concludes.

\section{2. (Im)Precise Probabilities Across Fields}

The idea that individuals might not hold precise probability distributions over uncertain events - and, thus, might not make decisions under uncertainty or update their beliefs at arrival of information as prescribed by Bayesian decision theory - has been investigated from multiple perspectives. 
In the field of statistics, between the 1960s and 1970s, Dempster and Shafer (Dempster, 1968; Shafer, 1976) developed a generalization of the Bayesian theory of subjective probability, featuring upper and lower probabilities obtained from single independent observations and a rule of conditioning that generalizes Bayesian conditioning. Further foundational efforts followed in the 1980s and 1990s, sometimes under the nomenclature of robust Bayesian analysis. These include Walley (1991)'s imprecise probabilities framework and Kuznetsov (1991)'s and Weichselberger (2000)'s works on interval statistical models and interval probabilities. Berger (1994) provides an overview of the field and a comprehensive literature review.

Philosophers, too, have developed alternatives to strict Bayesianism. Among early examples are the convex Bayesianism of Levi $(1974,1980)$ and the intervalism of Kyburg $(1961,1983)$. More recent developments include the set Bayesianism of Kyburg and Pittarelli (1992) and other settings of imprecise Bayesianism and ambiguity; see reviews by Kyburg and Teng (2001) and Bradley (2017). Some of these theories have been formally connected to one another. For example, Kyburg (1987) showed that the Dempster-Shafer theory is a special case of convex Bayesianism.

The research on imprecise probabilities in philosophy, statistics, and axiomatic decision theory is largely normative in nature. That is, it is concerned with how people should make decisions under uncertainty or how they should form expectations. ${ }^{9}$ Our analysis, on the other hand, is descriptive (or positive) in nature. Notwithstanding this important difference, our analysis shares with these literatures the idea that imprecise probabilities have the form of probability intervals.

Psychologists, behavioral decision researchers, and risk analysts, too, have long studied judgement and decision making under uncertainty. As consequential real-life decisions often depend on forecasts and opinions that individuals communicate to one another, psychological and related research has devoted considerable attention to how people communicate uncertainty (e.g., Budescu and Wallsten, 1995) and to the related topic of measuring people's probability judgments (e.g., Wallsten 1974; Wallsten and Budescu, 1983).

Most of this research, which is measurement-based and empirical in nature, has focused on precise probabilistic risk perceptions and risk communication (e.g., Morgan and Henrion, 1990; Morgan et al. 2001). However, a group of psychologists have investigated how people use and understand linguistic vis-à-vis numerical expressions of probability in relation to information processing and decision making (e.g., Budescu, Weinberg, and Wallsten, 1988; Wallsten,

${ }^{9}$ Although axiomatic decision theorists may disagree sharply on which axioms should be followed (Binmore, 2008). 
Budescu, and Zwick, 1993; Wallsten et al. 1993). Their research has concentrated on the study of experts and of situations where individuals' knowledge may be imprecise due to stochastic uncertainty and/or linguistic inexactness (e.g., Zwick and Wallsten, 1989; Wallsten, 1990). The latter may possibly occur when uncertain events and/or people’s opinions are vaguely formulated (e.g., Wallsten and Budescu, 1983; Budescu and Wallsten, 1987).

Among economists, the most common approach to carry out empirical research on uncertainty has been to analyze observed or stated choices using the principle of revealed preference, as in structural econometrics or experimental economics. However, as multiple combinations of utility, expectations, and choice sets may be consistent with the same observed choices, strong and often not credible assumptions are required to separately infer preferences and expectations from observed choices. See Manski (2007) for a textbook discussion of this identification problem.

An alternative possibility is to directly ask individuals. The growing economic literature on subjective expectations exemplifies this second approach. In this literature, subjective probabilities have been elicited directly from survey respondents using a numerical scale of percent chance, rather than being modelled and/or inferred from choices. These data have been used to estimate random utility models of choice under uncertainty and to study how individuals update expectations in real life. Manski (2004, 2018a), Attanasio (2009), Hurd (2009), van der Klaauw (2012), Armantier et al. (2013), Delavande (2014), Schotter and Trevino (2014), Giustinelli and Manski (2018), and Altig et al. (2019), among others, trace the development of the subjective expectations literature from various perspectives and in different economics subfields.

Most of this literature has maintained that respondents hold precise probabilities and has used subjective expectations data at face value. However, many questions posed in surveys of subjective expectations refer to events over which some respondents might not easily have or be able to form precise probabilities. Moreover, we know from our own work and the work of others that people may be willing and able to report probabilities in multiple ways. Thus, the fact that survey participants routinely answer these questions using the format of the question does not automatically imply that their beliefs are of that form.

In this paper, we take a direct approach to measurement and analysis of subjective probabilities. In this respect, our approach is similar to that used in psychology and in the survey expectations literature in economics. However, our analysis differs from most of the psychology and survey expectations literature, in that we develop an elicitation procedure that allows 
respondents to report precise (point) probabilities or imprecise (interval) probabilities. Moreover, relative to the small psychological literature on imprecise probabilities, we study non-experts and collect probabilistic expectations data in a nationally representative sample of older Americans.

Our interest in the possibility that people may hold imprecise probabilities derives in part from our previous studies of rounding of probability reports by HRS respondents. It has been found repeatedly that survey reports of numerical probabilistic expectations display substantial heaping at multiples of 5 and 10 percent, especially 0, 50, and 100 percent. This data pattern suggests that survey expectations are rounded. See Dominitz and Manski (1997) for an early discussion.

Manski and Molinari (2010) and Giustinelli, Manski, and Molinari (2019), whose findings inform our current study, analyzed respondent-specific response patterns across several expectations questions in the HRS. Using one and seven waves of data respectively, they found strong evidence of rounding, with the extent differing across respondents' characteristics and question domains, which in the HRS range from personal health to personal finances to macroeconomic events. Giustinelli, Manski, and Molinari (2019) further discovered that rounding tendencies vary across locations of the percent-chance scale, with respondents applying more rounding in the center (25-75 percent) than in the tails (below 25 and above 75 percent).

These papers proposed use of a person's response pattern across questions - and in the case of Giustinelli, Manski, and Molinari (2019) also across waves - to infer the person’s rounding practice or “type.” The result is interpretation of reported numerical values as interval data. Each interval represents the range of values in which the respondent's underlying true belief is plausibly deemed to lie based on the respondent's inferred rounding type. These intervals can be interpreted as a measure of the informativeness of probabilistic expectations data in the HRS.

In our new study, we develop and field a series of probing questions to directly elicit the extent to which individuals round or approximate their responses, and if they hold imprecise probabilities.

\section{Measuring Precise and Imprecise Probabilities}

\subsection{Probabilistic Expectations in the Health and Retirement Study}

From the early 1990s on, economic surveys have increasingly measured respondents' subjective expectations for future events using a 0-100 scale of percent chance; see Dominitz and Manski (1999) and Manski (2004) for historical treatments. The HRS has been at the forefront of 
measurement of economic expectations of older U.S. households in multiple domains of personal and macroeconomic uncertainty (e.g., Juster and Suzman, 1995; Hurd, 2009).

From 2002 on, for each of the biennial waves to date, Section P of the HRS Core questionnaire has been devoted to eliciting expectations on a $[0,100]$ percent chance scale. It poses about 25 to 35 questions spanning the domains of personal health, personal finances, and general economic conditions, with many repeated across waves.

Additional expectations data have been collected in selected HRS waves and from specific subsets of HRS respondents by means of so called "Experimental Modules." An experimental module is a short battery of questions, which HRS respondents are invited to answer after completing the Core questionnaire. Since the study's beginning, 9 to 12 experimental modules have been fielded at every wave, each on a random sub-sample of respondents. For the analysis of this paper, we use expectations data from an experimental module designed by us and fielded in the 2016 wave of the HRS. The next sub-section describes the design of the module.

\subsection{HRS Experimental Module on Dementia and Long-Term Care Probabilities}

Our module elicits expectations for future events regarding development of dementia, longterm care (LTC) decisions, and their relationship, from a random sub-sample of 1,293 eligible participants in the 2016 wave of the HRS. Module eligibility required that respondents did not live in a nursing home at the time of the survey and had never been diagnosed with Alzheimer disease or other forms of dementia. Combined with the fact that HRS respondents are aged 50 and over, these eligibility criteria select dementia-free individuals at risk of developing late-onset dementia as they age. They are not at risk of early-onset dementia.

Eligible respondents were randomly assigned to one of two question sequences regarding a distinct LTC outcome: purchasing LTC insurance or entering a nursing home. Overall, each respondent was asked about their expectations for four outcomes: purchasing LTC insurance (or

entering a nursing home), developing dementia, and purchasing LTC insurance (or entering a nursing home) if they knew the true dementia state (not developing dementia or developing dementia).

We discuss the LTC questions and analyze responses to them in separate research in progress. The substantive analysis of this paper focuses on the question asking respondents to report the percent chance of developing dementia in the future. 
All respondents taking the module were asked for their expectation of developing dementia. The question was worded as follows:

Q0. Dementia is a general term for a decline in mental ability severe enough to interfere with daily life. Memory loss is an example. Alzheimer's is the most common type of dementia. On a scale of $\odot$ to 100 , what is the percent chance that you will develop dementia sometime in the future?

This question features the same format as the standard expectations questions in Section P of the HRS Core questionnaire. Respondents are asked to answer it with a number between 0 and 100 percent, where 0 means that there is no chance that the event described in the question will happen and 100 means that the event is certain to happen. When a respondent insists that they do not know the chance of the event, their response is recorded as "Don't know" (DK). If a respondent refuses to answer the question, their response is recorded as "Refuse" (RF). ${ }^{10}$

Compared to the standard format, the module has a number of distinctive features and measurement innovations. These enable us to provide novel empirical evidence regarding the precision of probabilistic expectations in the domains of dementia and LTC and to shed light on the consequences that heterogeneously (im)precise probabilities can have for interpretation of current survey measures of probabilistic expectations in economic surveys.

The first new feature is that each of the four expectation questions in the module is followed by a follow-up sequence, probing to learn whether respondents were rounding or approximating their initial response and, if so, the extent and reasons for rounding. The purpose of the probing questions is to classify respondents in terms of the precise or imprecise nature of their probabilistic beliefs and also in terms of their tendency to report beliefs exactly or in rounded form.

We designed three probing sequences, one for each of three types of answer a respondent might give to the expectation question: (i) a numerical point response between 0 and 100 percent; (ii) a numerical interval response such as "between 30 and 60 percent” or "less than 80 percent”; (iii) a DK response.

\footnotetext{
${ }^{10}$ When a HRS respondent answers DK or RF to three consecutive expectations questions in Section P of the Core questionnaire, the respondent is skipped to the first applicable question of the next section. We apply a similar protocol and skip to the end of the module respondents who answer DK or RF to three consecutive expectations questions.
} 
Recall that the standard format used in the HRS Core does not allow respondents to answer with an interval. If a respondent happened to answer with an expression conveying a range of chances, the interviewer is instructed to ask the respondent to convert their answer into a single value. On the contrary, in our module we decided to keep record of "spontaneous" interval responses. In a separate follow-up question (described below), we asked respondents to convert their initial interval response into a point response. This approach enables us to learn the range of values that first came to the respondent's mind, alongside the "forced" point response which would be elicited according to the standard format.

We first describe the sequence of probing questions following a point response to any initial expectation question. Next, we describe the other two sequences, following respectively an interval response and a Don't Know response. ${ }^{11}$

Probing sequence after a numerical point response. The sequence of follow-up questions after a numerical point response is structured as follows.

Point FU Q1. When people are asked to give a numerical response, like percent chance, sometimes they give exact answers and sometimes they give rounded or approximate numbers. When you said [X] percent just now, did you mean this as an exact answer or were you rounding or approximating?

Possible answers: Exact answer; Rounding/approximating; Don’t know/Refuse.

Respondents indicating that their point response was exact were asked the next expectation question. Respondents indicating that they were rounding or approximating were asked a second probing question.

Point FU Q2. Now please try without rounding or approximating your answer. What is the percent chance that [EVENT] sometime in the future? If you are uncertain about the chances, you may give a range. For example, you may say something like "less than 20 percent," "between 30 and $4 \odot$ percent" or "greater than $8 \odot$ percent."

\footnotetext{
${ }^{11}$ The survey instrument can be downloaded from the HRS webpage, following: Researcher Site, Documentation, Questionnaires, 2016, Experimental Module 6 (https://hrs.isr.umich.edu/documentation/questionnaires).
} 
Possible answers: A percent chance in 0-100; a closed or open from below/above range; Don’t know/Refuse.

Probing sequence after a numerical interval response. Respondents who answered the expectation question with a spontaneous interval response were asked the following probing question before being routed to the next expectation question.

Interval FU Q1. If you had to answer with a single value to the previous question, what point would you give?

Possible answers: A percent chance in 0-100; Don’t know/Refuse.

Probing sequence after a Don't Know response. Respondents who insisted that they did not know the chance of the behavior or state whose expectation they were asked to report, were asked the following probing questions.

DKFU Q1. When people are asked to give the percent chance that something will happen in the future, sometimes they give exact answers and sometimes they feel uncertain about the chances. When you said you don't know just now, did you mean you feel uncertain about the chances or something else? Possible answers: Uncertain about the chances; Something else; Don’t know/Refuse.

Respondents indicating that they were uncertain about the chances were asked a second followup question; all other respondents were skipped to the next expectation question.

DK FU Q2. If you are uncertain about the chances, you may give a range instead. For example, you may say something like "less than 20 percent," "between 30 and $4 \odot$ percent" or "greater than 80 percent." If you could give a range, what range would you give to the percent chance that [EVENT] sometime in the future? Possible answers: A percent chance in 0-100; a closed or open from below/above range; Don’t know/Refuse.

Supplementary Appendix Figure S1 graphically displays the feasible survey paths following any of the four expectations questions asked in the module (unconditional dementia probability, 
unconditional LTC probability, conditional LTC probability given no dementia, and conditional LTC probability given dementia). The displayed paths are mutually exclusive across alternative initial answers to the expectation question. In general, a respondent might follow different paths when responding to different expectations questions.

For each expectation question asked in the module, we use the answers to the corresponding probing questions to classify respondents' responses into one of four mutually exclusive and exhaustive categories. Each category is defined by whether the respondent holds a precise or imprecise probability about the event in question and by whether the respondent reported the probability exactly or as a rounded number. The answers of respondents who gave an exact point response to the expectation question are classified as "Exact point probabilities." The answers of respondents who gave a rounded or approximated point response followed by an unrounded point response are classified as "Rounded/approximated point probabilities." The answers of respondents who gave a rounded or approximated point response followed by an interval are classified as "Interval probabilities." This category further includes the probabilities of respondents who spontaneously answered the expectation question with an interval and those who answered DK because they felt unsure about the chances. The answers of all remaining respondents are labelled as “Other.”

\section{4. (Im)precision of Subjective Probabilities of Developing Dementia}

This section and the next analyze the responses of HRS respondents when answering the dementia question, focusing on (im)precision here and the substantive findings in Section 5. Our analytic sample consists of 1,255 respondents for whom we have complete and logical responses. We drop 38 whose answers feature illogical values or patterns.

We exploit answers to the probing questions previously described to distinguish cases in which respondents round or approximate their reports even though they hold precise probabilistic beliefs and cases where respondents round or approximate to convey imprecise probabilities. Specifically, we distinguish three groups of persons: - those who state that their initial responses were exact numbers, called group EX; - those who rounded/approximated and who reported precise probabilities after probing, called group PR; and - those who rounded/approximated and who reported probability intervals after probing, called group IM. 
Both here and later in the paper, we maintain the working assumption that the responses that persons give after probing express their "true" expectations, be they precise or imprecise. Being unable to directly observe the cognitive processes of respondents, we cannot be certain that this assumption is universally accurate. We use it because we think it to be reasonably valid and because it offers a coherent framework for empirical analysis of the HRS data.

Subsection 4.1 documents the prevalence and extent of (im)precision of subjective dementia probabilities and describes how these vary across respondents with different observed characteristics. Considering respondents who initially give "focal" responses of 0 , 100, or 50 percent, we assess the implications of the empirical evidence for the realism of some theories in economics and psychology that hypothesize respondent use of focal values to express uncertainty. Subsection 4.2 studies the relationship between initial and post-probe reports of dementia probability.

\subsection{Patterns of (Im)Precision}

Column 1 of Table 1 displays the empirical distribution of the three probabilistic response groups and the small remainder who could not be classified.

About half of the respondents express precise probabilities of developing dementia (49.2\%) after probing, and almost as many express imprecise probabilities (46.5\%). The latter include 6.5\% of respondents who spontaneously gave an interval of percent chance in response to the initial probability question. ${ }^{12}$ The response of the remaining $4.4 \%$ of respondents could not be classified due to DK/RF responses to the initial and/or probing questions.

Our probing sequence thus reveals that nearly half of the HRS respondents taking our module hold imprecise subjective probabilities about future dementia status. These respondents are capable and willing to quantify the extent of their uncertainty by means of a range of percent chance when given the option to do so. Absent this option, as in the standard HRS question format, cooperative respondents tend to report imprecise subjective probabilities as rounded point responses. This evidence is consistent with the hypothesis advanced by Manski and Molinari

\footnotetext{
${ }^{12}$ Recall that respondents were initially asked to give a precise probability. The fact that 6.5\% initially gave an interval may reflect the ordering of questions in the experimental module. Respondents were first asked to give their LTC expectations, which introduced the possibility of giving an interval response after probing. It may be that familiarizing respondents with interval probabilities in that context opened the way for the $6.5 \%$ to use the format spontaneously when answering the ensuing dementia question.
} 
(2010) that the common tendency of survey respondents to give rounded responses to probabilistic expectations questions may reflect imprecision in their underlying beliefs.

To gauge the extent of the imprecision, Table 2 displays the $1^{\text {st }}$ decile, median, and $9^{\text {th }}$ decile of the empirical distribution of interval widths among respondents with imprecise probabilities. These statistics are shown separately for the sub-sample of respondents who answered the initial dementia question with a point probability and the post-probe question with a probability interval (Column 1) and for the sub-sample of respondents who answered the initial dementia question with a spontaneous interval (Column 5).

Notwithstanding the difference in survey behavior between the two sub-samples of respondents, the empirical distributions of interval widths are quite similar across the two. In the two groups, $28 \%$ and $29 \%$ of respondents have interval width equal to 10 percent, while $33 \%$ and $21 \%$ have interval width equal to 20 percent. Thus, the median interval width is 20 percent in both sub-samples. The $1^{\text {st }}$ and $9^{\text {th }}$ decile are respectively 10 and 80 percent in both sub-samples, yielding identical measures of variation (70 percent).

Before commenting on the remaining figures in Tables 1 and 2, it is important to observe in Column 1 of Table 1 that, among the respondents who give precise dementia probabilities after probing, 30\% report that their initial responses were rounded or approximated. Thus, our probing sequence reveals that the practice of rounding or approximating probability reports in expectations surveys is not limited to respondents with imprecise probabilities. Some respondents may round or approximate their probability reports to simplify communication, as hypothesized by Manski and Molinari (2010).

Columns 2 through 4 of Tables 1 and 2 respectively display the empirical distributions of probabilistic response types and of interval widths for respondents who answered the initial probability question with the value 0 percent (Column 2), 50 percent (Column 3), or an answer other than 0 and 50 percent (Column 4). 0 and 50 percent (together with 100 percent) are sometimes referred to as "focal” responses in the subjective expectations literature. Some authors have devoted special attention to the analysis of these responses and have advanced specific hypotheses about their meaning and interpretation.

Fischhoff and Bruine de Bruin (1999) and Bruine de Bruin et al. (2002), for instance, hypothesize that some respondents use 50 percent to signal epistemic uncertainty, meaning extreme imprecision in beliefs. Lillard and Willis (2001) and Hudomiet and Willis (2013) 
conjecture that respondents form precise subjective distributions for the probability of an event and then, perhaps to simplify communication, they report whichever of the values $(0,50,100)$ is closest to the mode of their distribution. This is termed the "modal response hypothesis." The statistics shown in Columns 2-4 of Tables 1 and 2 enable us to empirically assess these hypotheses. We do not report the distributions for respondents who initially answered 100 percent because few respondents did so (less than 1\%).

We find that respondents who initially gave a response of 0 percent are substantially more likely to report after probing that their response is exact (73.3\% vs. $34.8 \%$ in the whole sample), somewhat less likely to report that their response is a rounded or approximated point probability (8.3\% vs. $14.3 \%$ in the whole sample), and substantially less likely to provide a probability interval (15.5\% vs. $46.5 \%$ in the whole sample). These results are contrary to the modal response hypothesis, which conjectures that responses of 0 percent tend to reflect substantial rounding.

Respondents who initially gave a response of 50 percent are somewhat less likely to report that their response is exact ( $27.9 \%$ vs. $34.8 \%$ in the whole sample), more likely to report that their response is a rounded or approximated point probability (23.6\% vs. $14.3 \%$ in the whole sample), and just slightly more likely to give an interval when permitted to do so (47.6\% vs. $46.5 \%$ in the whole sample). These results seem inconsistent with the epistemic-uncertainty hypothesis, which conjectures that responses of 50 percent tend to reflect substantial imprecision in beliefs. Indeed, the pattern of the interval-width distributions across subsamples shown in Table 2 further supports no differential imprecision of dementia probabilities between respondents who initially answered with 50 percent and respondents who answered with numbers other than 50 .

We conclude this sub-section by investigating whether, and if so how, the prevalence of different probabilistic response types and the amount of probability imprecision vary with observed respondent characteristics.

To this end, we first estimate multinomial probit regressions of probabilistic response type as a function of respondent age, gender, race, and education. A second specification adds an HRS measure of cognition. The estimates are reported in Table S1 of the Supplementary Appendix. Next, we estimate mean linear regressions of interval width conditional on the same vectors of covariates among respondents with imprecise dementia probabilities. These estimates are reported in Table S2 of the Appendix. Here we summarize the findings reported in Table S1. See the Appendix for further discussion of these findings and of those in Table S2. 
We find that older respondents are more likely than younger ones to report rounded or approximated probabilities and to hold interval probabilities. More educated respondents are less likely to report a rounded or approximated probability and are more likely to hold imprecise probabilities. Black respondents are less likely than others to report rounded/approximated probabilities as well as to hold imprecise probabilities. We find no significant association between probabilistic response type and gender, or between probabilistic response type and measured cognitive ability.

\subsection{Relationship between Initial and Post-Probe Subjective Probabilities}

We now study the relationship between the initial and post-probe dementia probabilities in groups PR and IM. To begin, Table 3 shows a cross-tabulation of initial responses and post-probe responses among respondents in group PR, that is, respondents whose initial responses are rounded point-probabilities and their post-probe responses are unrounded point-probabilities. Responses are aggregated into categories to facilitate the presentation. Over half of these respondents (51.7\%) reported initial and post-probe probabilities in the same response category; that is, along the diagonal of the cross-tabulation. In fact, over $60 \%$ of the respondents on the diagonal of Table 3 gave a post-probe response identical to the initial response. Among the respondents off the diagonal, 3 out of 4 gave a post-probe response of finer granularity than the initial-probe response, while the remaining respondents (12.2\% of the PR group) gave a coarser post-probe response than their initial response.

Lacking a direct measure of rounding, our earlier work inferred the amount of person-specific rounding from the person's pattern of response granularity across multiple expectations questions, within and across survey waves (Manski and Molinari (2010) and Giustinelli, Manski, and Molinari (2019)). The motivating logic behind this inferential approach is that responses that are multiples of 10 percent are more likely to be rounded than responses that are multiples of 5 percent (but not of 10 percent) and, in turn, the latter responses are more likely to be rounded than responses that are multiples of 1 percent (but not of 5 percent). If granularity of responses conveys information about the underlying amount of rounding, the figures in Table 3 provide evidence supporting the ability of our probing sequence to elicit post-probe responses that are on average less rounded than initial responses among PR respondents. 
Table 4 compares initial and post-probe dementia probabilities for respondents in group IM. Note that this entails comparing a point probability with an interval probability. To ease the exposition, we again aggregate responses into categories and examine the initial and post-probe responses. The categories we use are: (a) the point probability equals the midpoint of the probability interval; (b) the point probability lies inside the probability interval but differs from the midpoint; (c) the point probability lies outside the probability interval, its distance from the closest boundary of the interval being at most 5 percentage points; (d) the point probability lies outside the probability interval, its distance from the closest boundary being between 6 and 10 percentage points; and (e) the point probability lies outside the probability interval, its distance from the closest boundary being greater than10 percentage points.

The top panel of Table 4 shows the empirical distributions of these point-interval comparison categories among all persons in group IM who gave a point followed by an interval and then disaggregated by the width of the interval. The bottom panel reports analogous distributions for respondents who gave a spontaneous interval followed by a forced point.

Focusing on the 442 respondents in the top panel, we find that the post-probe interval contains the initial point response for approximately $69 \%$ of respondents, including $11 \%$ for whom the initial point probability equals the midpoint of the interval. Among the remaining $31 \%$ of respondents, the post-probe interval does not contain the initial point. In most cases, the distance of the point response from the boundary of the interval is either between 6 and 10 percentage points or greater than 10 percentage points. Disaggregation of respondents by interval width reveals that, as expected, the fraction of point responses lying inside the corresponding interval is lowest (60.6\%) among respondents with narrow intervals (width $(0,10]$ percent) and highest $(77.0 \%)$ among respondents with wide intervals (width (20-100] percent).

These patterns, however, do not seem to apply to the relatively small group of 78 respondents in the bottom panel, who gave a spontaneous interval and were then probed for a point response. Over $90 \%$ of these respondents give a forced point inside the initial interval. This result essentially holds for all interval widths.

Tables 3 and 4 describe the relationship between initial and post-probe responses in an agnostic manner, not taking a position on the cognitive process that relates the responses. In the remainder of this section, we reinterpret the empirical evidence under our assumption that post-probe responses convey the underlying beliefs of respondents. From this perspective, a person's initial 
response is a rapid and potentially error-ridden measure of her underlying belief. Their post-probe response is an error-free measure expressed after some reflection. To analyze the relationship between post-probe and initial responses from this perspective, we calculate the empirical expectation of initial responses, now called $y$, conditional on post-probe responses, now called $x$.

Panel A of Table 5 shows these estimates for respondents in group PR. The table reports $E(y \mid x)$ for $x \in\{0,10,20,30,40,50,60,70,80,90,100\}$, along with asymptotic 95\% confidence intervals. Panel B likewise shows these estimates for respondents in group IM, now defining $x$ to be the lower bound and width of the interval probability. In this case, we report estimates for values of the lower bound that are multiples of 10 and for width equal to 10 or 20 . Recall that respondents with interval width equal to 10 or 20 make up over $60 \%$ of group IM.

In addition to the estimates in Table 5, we performed non-parametric kernel regressions of $y$ on $x$, which we report graphically in Figure 1. These estimates are obtained in Stata, using the Gaussian kernel and cross-validation bandwidth. Since the results in Table 5 and Figure 1 convey the same main findings, we discuss them together. Nevertheless, we thought it useful to report the non-parametric estimates graphically, along with a scatterplot of the data, as they summarize and communicate important information in an effective way.

While this regression is straightforward for group PR (reported in the top left panel of Figure 1), some care is needed for group IM. In this case $x$, the post-probe report, is set valued. We carry out the task by focusing on the subsamples of group IM with interval width equal to 10 (bottom left panel of Figure 1) and equal to 20 (bottom right panel). For each subsample, we run a standard kernel regression of initial response on the LB of the post probe response.

Along with the estimated kernel regression function (in blue), each graph displays the 45degree line (in red) and the scatterplot of the initial probability answer, $y$, against the post-probe probability answer, $x$ (green dots). The size of each dot is proportional to the relative frequency of the corresponding observation.

The scatter plot illustrates large heterogeneity in initial-response conditional on post-probe response. It is also suggestive of a pattern where small probabilities in the post-probe report were much larger in the initial report, and vice versa for large probabilities. This observation is confirmed in Table 5 and in the kernel regressions.

The estimated function starts at a positive value, between 10 and 20 percent, at $x=0$ and initially runs above the 45-degree line. At values of $x$ between 40 and 50 percent, the estimated 
function begins to flatten out and it eventually crosses the 45-degree line between $x=50$ and 60 percent. After that, the function continues to increase throughout the empirical support of $x$, while remaining below the 45-degree line.

In the bottom-left graph, where respondents in group IM have interval width equal to 10 , the scatterplot of $y$ conditional on $x$ is also quite dispersed, particularly for respondents whose interval LB equals 30 percent. In this graph, the estimated kernel function starts just below 10 percent at $x$ $=0$ and continues above the 45-degree line throughout the empirical support of $x$. Some flattening out is observed between 20 and 40 percent, where the bulk of the observations lie.

The flattening out of the kernel function is more pronounced for respondents with interval width equal to 20 percent, shown in the bottom-right graph. In this case, the estimate of $\mathrm{E}(y \mid x)$ starts quite high (at around 20 percent) for LB values between 0 and 15 percent. Then it climbs steeply, until it begins to flatten out at values of the LB of 30 percent and higher, crossing the 45degree line at around 60 percent.

It is important to note that, in this case, the vast majority of the observations have interval LB equal to 0 , with only a handful of observations featuring a strictly positive LB. Indeed, zero is the only LB value where a widely dispersed scatterplot of initial-probe dementia probabilities is observed.

\section{Magnitudes of Subjective Probabilities of Developing Dementia}

Section 4 described the precision of respondent subjective probabilities in an abstract manner, not discussing dementia as a substantive concern of health economics and public health. Perceptions of dementia risk are potential determinants of multiple important decisions made by older persons, from precautionary savings choices to the timing of retirement to purchase of longterm care insurance. To the best of our knowledge, our work provides the first empirical evidence on how older persons perceive their risks of developing dementia. We now discuss the findings from this substantive perspective.

Table 6 presents the empirical distributions of responses to the dementia probability question in our three main groups of respondents, as measured by their responses after probing. Column 1 of the table describes the response distribution of group EX. We elicited only one probability report from these persons. Columns 2 and 3 describe the initial response distribution of groups PR and IM. Columns 4 through 6 describe the responses of these groups after probing. The post-probe 
response is a precise probability in group PR and an interval in group IM. Columns 5 and 6 show the lower bound (LB) and upper bound (UB) distributions for group IM.

In each column, the top part of the table reports the frequency of responses that equal 0,50 , 100 , another single value, or an interval value, while the bottom part reports the $1^{\text {st }}$ decile, median, mean, and $9^{\text {th }}$ decile of the response distribution. Table S3 in the Supplementary Appendix provides the same distributions at a greater level of granularity.

The data in Table 6 may be analyzed in at least two ways. One is to compare initial and postprobe responses within each response type, adding further texture to the analysis we reported in Section 4.2. The other focuses on the post-probe responses, which we interpret as expressing respondents' underlying beliefs. In this section we describe the post-probe responses and compare them to a few available statistics on the lifetime risk of developing dementia for subgroups of the American population broadly comparable to our sample.

Column 1 of Table 6 shows that 34.6\% of respondents in group EX assign an exact probability of 0 to the event of developing dementia in the future and $1.6 \%$ assign probability 1 . The remaining $63.9 \%$ of respondents views developing dementia as an uncertain event to which they assign a probability strictly between 0 and 1 . In this latter group, nearly $15 \%$ of respondents assign a 50 percent chance to developing dementia.

The frequencies of 0 and 100 percent post-probe responses vary substantially across response types. Whereas these frequencies are $34.6 \%$ and $1.6 \%$ in group EX, they are only $4.4 \%$ and $0 \%$ in group PR. Among respondents in group IM, who report interval probabilities, 50\% give 0 percent as their interval LB and 16.2\% give 100 percent as their interval UB. The frequency of 50 percent responses is very similar for respondents in groups EX and PR, being 14.9\% and 15.0\%. For respondents in group IM, the frequency of 50 percent is close to $5 \%$ of the LB responses and close to $10 \%$ of the UB responses.

Regardless of their probabilistic response type, the HRS respondents display a wide range of beliefs about dementia risk. Among those in group EX, the $1^{\text {st }}$ decile of the empirical distribution of subjective dementia probabilities is equal to 0 and the $9^{\text {th }}$ decile is equal to 70 , implying a $1^{\text {st }}$ $9^{\text {th }}$ decile range of 70 percent. The corresponding measure of variation in group PR is 60 percent, the $1^{\text {st }}$ and $9^{\text {th }}$ deciles being 10 and 70 percent. In group IM, the $1^{\text {st }}-9^{\text {th }}$ decile range of LB responses is 40 percent, the $1^{\text {st }}$ and $9^{\text {th }}$ deciles being 0 and 40 percent. The $1^{\text {st }}-9^{\text {th }}$ decile range of $U B$ responses 
is 80 percent, the $1^{\text {st }}$ and $9^{\text {th }}$ deciles being 20 and 100 percent. Only $1.8 \%$ of respondents report an interval of width 100 .

To measure central tendency, Table 6 reports the median and mean responses in the three groups. The median and mean probabilities of developing dementia equal 15.0 and 25.5 percent in group EX. They are 30.0 and 33.7 percent in group PR. The median LB and UB responses in group IM are 0 and 40 percent. The respective mean LB and UB responses are 15.6 and 45.8 percent.

Ideally, we would like to compare these reported probabilities with the future realized dementia status in our sample of respondents. Such a comparison will eventually be possible, as the HRS collects data longitudinally from its respondents. For now, it is only possible to compare the probabilities with available statistics. Most of the available statistics refer to the prevalence of dementia at specific points in time and among specific age groups (e.g., Plassman et al. (2007), Hudomiet, Hurd, and Rohwedder (2018)). However, prevalence of dementia at a point in time is a different concept from the risk of developing dementia by a certain age, or the lifetime risk of dementia for those groups.

As discussed in the introduction, currently there is a paucity of personalized information about lifetime risk of developing dementia. Thus, we can at best compare the precise and imprecise subjective probabilities that we elicited, with a small set of estimates of lifetime risk and related statistics obtained by the medical literature analyzing data from samples broadly comparable to ours in terms of age and focusing on late-onset dementia. These sources are Seshadri and Wolf (2007), Chene et al. (2015), and Fishman (2017). The first two use data from the Original and/or Offspring cohorts of the Framingham Heart Study (FHS), ${ }^{13}$ while the third one uses data from the Aging, Demographics and Memory Study (ADAMS). ${ }^{14}$

Using FHS data from the Original Cohort, Seshadri and Wolf (2007) estimate age- and genderspecific lifetime risk of dementia among FHS participants who were dementia-free at 55. Depending on age and gender, their estimates range between $14.3 \%(95 \% \mathrm{CI}=[12.0 \%, 16.2 \%])$

\footnotetext{
${ }^{13}$ The FHS is a longitudinal community-based cohort study that began in 1948. Members of the Original Cohort were 5,209 stroke- and dementia-free residents of Framingham, MA. These members have undergone biennial examinations (medical history, physical examination, and laboratory testing) and have been assessed for stroke incidence and dementia onset through the present. In 1971, the Offspring Cohort was recruited from children of the Original Cohort and their spouses; these 5,214 participants have undergone examinations approximately every four years. Dawber et al. (1951) and Kannel et al. (1979) describe the study design and selection criteria for the two cohorts.

${ }^{14}$ The ADAMS was conducted between 2001 and 2003 on a sub-sample of 856 HRS respondents aged 71 and older, who were evaluated for dementia using a comprehensive in-home assessment. See Plassman et al. (2007) and references therein for more detail on the ADAMS.
} 
and 24.3\% (95\% CI = [20.7\%, 27.8\%]) for all-type dementia, and between 9.1\% (95\% CI = [7.2\%, 11.1\%]) and 20.3\% (95\% CI = [17.0\%, 23.6\%]) for Alzheimer's Disease. More recently, combining the Original and Offspring cohorts, Chene et al. (2015) estimate gender-specific cumulative incidence of dementia for FHS participants who were dementia-free at 65 and/or at 45, adjusted to account for competing risks of death. This second set of estimates ranges between 13.8\% (95\% CI = [12.2\%, 15. 3\%]) and 24.6\% (95\% CI = [22.7\%, 26.5\%]) for all-type dementia, and between 10.3\% (95\% CI $=[8.9 \%, 11.8 \%])$ and $21.1 \%(95 \% \mathrm{CI}=[19.2 \%, 23.0 \%])$ for Alzheimer's Disease. Finally, combining information from the ADAMS and the HRS mortality tracking data, Fishman (2017) estimates the probability that a dementia-free person will develop dementia later in life for several starting ages (from 70 to 100 at intervals of five years) and for two cohorts of ADAMS participants (the 1920 and 1940 cohorts). These estimates range between 24.4\% (SE $=7.2 \%)$ and $37.4 \%(\mathrm{SE}=3.8 \%)$.

The range of realizations-based estimates is quite wide. Comparison with the results that we report in Table 6 - and those in Table 7 discussed below, which condition on demographic characteristics - suggests that this range is broadly similar to the range of precise and imprecise probability responses that we elicited.

To understand whether, and if so how, subjective dementia probabilities vary across age groups and socio-demographic characteristics of respondents, in Table 7 we report the sample means (along with standard errors) of the post-probe dementia probabilities, decomposed by age, gender, race, and education groups. In practice, for each socio-demographic characteristic, we estimate a mean linear regression of dementia probability conditional on a set of dummy variables, each capturing a different level of that characteristic. Thus, the coefficient of the omitted category gives the mean dementia probability in the reference group. Next to each estimated coefficient, we report the estimated mean of the corresponding group.

We perform these comparisons of means separately for respondents holding precise dementia probabilities (in Columns 1-2) and for respondents holding imprecise ones (in Columns 3-6). The precise-probability sub-sample in Columns 1-2 pools groups EX and PR, using the post-probe report for group PR. We refer to this combined group as EX + PR. Because the dementia probability of respondents in group IM is measured as an interval, we report the estimated coefficients and means of both the interval LB (in Columns 3-4) and UB (in Columns 5-6). 
Columns 1-2 reveal that mean dementia probabilities vary non-monotonically with age in both groups EX + PR and IM. It first increases with age over the 60-69 range and then decreases at older ages. Only the changes at ages 60-69 compared to younger than 60 are statistically different from zero.

Female respondents have higher mean dementia probabilities than male respondents in our sample. Observed differences, however, are quite small and never statistically significant.

Black respondents report lower dementia probabilities on average than white respondents, statistically significant in group EX + PR. In group IM, black respondents tend to give higher UB probabilities of dementia. Respondents of other race have lower dementia probabilities than white respondents in group EX + PR and higher interval LB and lower interval UB in group IM (none of these differences is statistically significant).

In group EX + PR high school graduates, respondents with some college, and those with a college degree hold statistically significantly higher dementia probabilities than respondents with no diploma. In group IM only respondents with some college and those with a bachelor degree have higher dementia probabilities than no-degree respondents on average (statistically significant).

In Table S4 of the Supplementary Appendix, we further report estimates of multivariate best linear projections of dementia probability conditional on the entire vector of covariates, both for group EX + PR using standard methods and for group IM using methods from the partial identification literature. We think it interesting to do so, as some of the univariate correlations between dementia status and individual socio-demographic characteristics documented in the medical literature may actually change when one conditions on multiple characteristics simultaneously.

\section{Implications for Decision Making}

Scholars working in different fields have long been concerned that individuals facing uncertain decisions with limited information might hold imprecise probabilities. However, evidence on this phenomenon has been scant. In this paper, we have documented that in a random sub-set of HRS respondents, nearly half have imprecise probabilities of developing late-onset dementia in the future. To the extent that perceptions of dementia risk matter for economic decisions such as when 
to retire or whether to purchase LTC insurance, our findings carry implications for prediction and modeling of economic behavior.

Here, we provide an example illustrating the potential implications of imprecise dementia probabilities for prediction of LTC insurance purchase. The example adapts analysis of medical decision making under ambiguity in Manski (2018b).

Consider the following choice problem, with a person deciding whether or not to purchase LTC insurance. The decision is denoted by $d$, where $d=1$ if the person buys LTC insurance and $d=0$ otherwise. Utility depends on an uncertain state of nature, which is also binary. The state is denoted by $s$, where $s=1$ if the agent develops dementia in the future and $s=0$ otherwise. The decision, $d$, does not affect the probability of the state, $s$. This is realistic when the state indicates dementia. State-dependent utility, $U(d, s)$, satisfies the inequalities

$$
\left\{\begin{array}{l}
U(1,1)>U(0,1) \\
U(1,0)<U(0,0) \\
U(d, 0)>U(d, 1) \quad \forall d \in\{0,1\} .
\end{array}\right.
$$

That is, the person prefers being insured in the dementia state and not being insured in the dementia-free state. Conditional on a choice, the decision maker's utility is higher in the dementiafree state than in the dementia state.

In a standard Bayesian setting, the decision maker has a precise subjective probability $P_{s}$ for developing dementia in the future. The optimal decision is the action that maximizes the person's subjective expected utility (SEU),

$$
d^{*}=\left\{\begin{array}{l}
1 \text { if } P_{s} \cdot U(1,1)+\left(1-P_{s}\right) \cdot U(1,0) \geq P_{s} \cdot U(0,1)+\left(1-P_{s}\right) \cdot U(0,0) \\
0 \text { otherwise, }
\end{array}\right.
$$

or equivalently,

$$
d^{*}=1 \text { if } P_{s} \geq P^{*}=\frac{U(0,0)-U(1,0)}{[U(1,1)-U(0,1)]+[U(0,0)-U(1,0)]} .
$$

Now introduce imprecision and assume that the decision maker has an imprecise interval probability, $\left[\mathrm{P}_{\mathrm{L}}, \mathrm{P}_{\mathrm{H}}\right]$. Recall that nearly half of our respondents gave post-probe dementia probabilities of this form. Criteria for decision-making with imprecise probabilities include maximin (MM) and minimax-regret (MMR). 
A MM decision maker evaluates each action by the worst SEU that it might yield and chooses an action with the least-bad worst SEU. The worst feasible SEUs for $d \in\{0,1\}$ occur when $P_{s}=P_{H}$. Hence, the MM choice is $d^{*}=1$ if $P_{H} \geq P^{*}$. A MMR decision maker, on the other hand, evaluates each action by the worst reduction in SEU that it might yield vs. the highest SEU achievable. Hence, the MMR choice is $d^{*}=1$ if $P_{M} \geq P^{*}$, where $P_{M}$ is the midpoint of $\left[P_{L}, P_{H}\right]$. See Manski (2018b) for details.

Given a fixed configuration of state-dependent utilities and associated threshold $P^{*}$, a MM decision maker would make a different choice than a Bayesian, as long as $P_{s}<P^{*} \leq P_{H}$. That is, when $P_{s}<P^{*} \leq P_{H}$, a MM decision maker would purchase LTC insurance, whereas a Bayesian would not. Similarly, when $P_{s}<P^{*} \leq P_{M}$, a MMR decision maker would buy LTC insurance, whereas a Bayesian would not. Finally, when $P_{M}<P^{*} \leq P_{H}$, a MM decision maker would purchase insurance, whereas a MMR decision maker would not.

For concreteness, consider a Bayesian (EX) with precise dementia probability equal to 0 percent, and two imprecise-probability (IM) persons with post-probe interval probabilities equal to $[0,20]$, one following $\mathrm{MM}$ and one MMR. Both probability responses, exact 0 percent and interval $[0,20]$ percent, are quite common in our data, as shown in Table 6 (column 1) and Figure 1 (bottom-right graph). In this example, the Bayesian would never buy insurance, unless $U(1,0) \geq U(0,0)$, which violates a credible assumption in our example, according to which the utility of buying insurance is lower than that of not buying it in the dementia free state (recalling that dementia is the only risk in this example). The MM respondent, on the other hand, would buy insurance as long as $P^{*} \leq 20$. The MMR respondent would buy insurance as long as $P^{*} \leq 10$.

In general, taking the initial response given by IM respondents as a summary statistic of their interval is not a good assumption. As we saw in Table 4, nearly 30\% of IM respondents give an initial point that is not contained in the post-probe interval, and only slightly over $10 \%$ of them give an initial point that coincides with the midpoint of the post-probe interval. In fact, the bottom graphs in Figure 1 show that many IM respondents give an initial point response that is higher than the UB of their post-probe interval. Whenever the decision threshold, $P^{*}$, lies between the interval $\mathrm{UB}, P_{H}$, and the initial point-response, using the latter as a statistics for the interval would lead to predict, incorrectly, that the agent will purchase LTC insurance. 
Finally, note that rounding by PR respondents can also affect accuracy of predictions. According to the top-left graph of Figure 1, PR respondents tend to give initial point-probabilities that are higher than post-probe probabilities when the latter are small, and lower than post-probe probabilities when the latter are high. Thus, using the initial point-probability of dementia in place of the post-probe probability to predict LTC insurance purchase when the post-probe probability of dementia is low will lead one to erroneously predict that the person purchases LTC insurance whenever the decision threshold, $P^{*}$, lies between the post-probe probability and the initial rounded probability. The opposite mistake would occur, when the rounded point-probability is above the post-probe probability and the decision threshold lies between the two.

\section{Conclusion}

This paper has proposed and applied an elicitation procedure that allows us to distinguish between respondents who hold precise probabilities about future events, and ones who hold imprecise probabilities, while also accounting for the fact that survey reports might be rounded or approximated. The elicitation mechanism first queries respondents about their percent-chance expectations employing a standard format used in the HRS, and then uses two probing questions to learn about the nature of people's reports. The first probe asks whether the reported probability was intended as an exact number or rounded/approximated. If the latter, a second probe asks for the non-rounded and non-approximated expectation, and permits respondents to report an imprecise probability in the form of a range.

We have fielded this elicitation mechanism as an experimental module in the 2016 HRS, to learn from a nationally representative sample of respondents about individuals' expectations of developing dementia in the future. As far as we are aware, our work provides the first empirical evidence on how older Americans perceive their own risk for this disease. Our analysis of the data reveals that nearly 50\% of respondents hold imprecise probabilities.

Compared to their post-probe responses, individuals holding precise probabilities have a tendency, when asked using the standard format, to over-report very small probabilities. They also tend to under-report large probabilities. A similar pattern is exhibited by respondents holding imprecise probabilities, compared with the lower bound of the interval that they report post probing, conditional on the width of the interval. 
Examining the magnitudes of individuals' expectations of developing dementia, within several demographic subgroups we find that those with precise probabilities expect to develop the disease on average with probabilities between $19.4 \%$ and 34.6\%. Respondents holding imprecise probabilities report average intervals with lower bounds between $10.9 \%$ and $23.5 \%$, and upper bounds between $42.0 \%$ and 55.1\%, again depending on the demographic subgroup analyzed. These expectations are usually within the range of existing estimates of lifetime dementia risk produced in the medical literature using U.S. data.

Understanding older persons' perceptions of dementia risk is important, because these perceptions can affect precautionary saving choices, timing of retirement, purchase of long term care insurance, and other decisions. Using a specific choice framework, we have shown that use of point-probability reports to predict choices of imprecise-probability agents and/or of rounded point-probability reports to predict choices of precise-probability agents would likely lead to prediction mistakes for common response configurations in our data.

To learn about the interaction between perceptions of dementia risk and LTC plans, our experimental module also asked HRS respondents about their expectations to purchase LTC insurance or move to a nursing home. The prevalence of imprecise probabilities, and the extent of imprecision as measured by the empirical distribution of the interval width, are similar across dementia and LTC outcomes. We think that relating dementia expectations to expectations on LTC choices is very important, but it is too complex a matter to study within this paper, as it requires too much space and distinct considerations. As such, we are pursuing it in a separate paper.

We think it also important to understand the sources of the imprecision in individuals' probabilities. To this end, we have introduced in our module a novel design where expectations about LTC choices are elicited unconditionally and then re-elicited under alternative information scenarios about hypothetical dementia conditions (developing dementia for sure, and not developing it for sure). This design enables us to investigate the relationship between information (or lack thereof) and (im)precision of probabilities. Preliminary results suggest that once they are informed that their risk of dementia is zero or one, the proportion of respondents reporting imprecise probabilities decreases substantially, ranging between $17 \%$ and $27 \%$ depending on the LTC outcome (purchasing LTC insurance or entering a nursing home) and conditioning dementia state (no dementia or dementia). 
Looking forward, we view the work reported in this paper as a natural next step advancing the research program on measuring expectations. Until the early 1990s, there were no large scale household surveys querying respondents about their subjective expectations in a probabilistic manner. Rather, there was attitudinal research which posed questions in verbal terms. In the 1990s, stimulated by innovative question formats posed in the HRS and other surveys, economists began collecting numerical probabilistic expectations data. This resulted in fruitful research, see Manski (2004) for a survey and discussion. Since then, the common practice has been to treat survey responses to probabilistic expectations questions as representing precise probabilities that respondents hold.

Nevertheless, we have been intrigued by the fact that respondents are able and willing to answer expectations questions in multiple ways, responding to verbal attitudinal queries and reporting numerical probabilities on scales of differing granularities (e.g., Olson and Budescu, 1997; Woloshin et al., 2000; Manski and Molinari, 2010). Even if they hold imprecise probabilities, individuals are able to report a single value when asked to do so. We think it natural to explore empirically the extent of imprecision in individuals' beliefs, thereby establishing a bridge with the theoretical and experimental research on ambiguity and its role in decision making. The elicitation mechanism utilized in this paper puts forward a concrete proposal for doing so.

We view our work as contributing to a new phase of measuring expectations, with important questions still to be addressed. Considerations of survey space emerge immediately: the probing questions in our elicitation module add length to the HRS instrument. While the empirical evidence suggests that our sequence of probes successfully elicits imprecise probabilities, more effective question formats might be possible. For example, a survey could directly offer to respondents the possibility to report their beliefs as intervals. It is also an open question whether imprecise probabilities should be elicited in all contexts, or only in those where imprecision seems a prominent concern. 


\section{References}

Altig, D. and J.M. Barrero and N. Bloom and S.J. Davis and B.H. Meyer and N. Parker. 2019. Surveying Business Uncertainty. NBER Working Paper 25956.

Alzheimer's Association. 2018. “Alzheimer's Disease Facts and Figures.” Alzheimers Dementia 14(3): 367-429.

Attanasio, O. 2009. "Expectations and Perceptions in Developing Countries: Their Measurement and Their Use.” The American Economic Review 99(2): 87-92.

Armantier, O. and W. Bruine de Bruin and S. Potter and G. Topa and W. Van der Klaauw and B. Zafar. 2013. “Measuring Inflation Expectations.” Annual Review of Economics 5: 273-301.

Berger, J.O. 1994. “An Overview of Robust Bayesian Analysis.” Test 3(1): 5-124.

Binmore, K. 2008. Rational Decisions. Princeton University Press.

Bradley, R. 2017. Decision Theory with a Human Face. Cambridge University Press.

Bruine de Bruin, W., P.S. Fischbeck, N.A. Stiber, and B. Fischhoff. 2002. "What Number is "Fifty-Fifty?”: Redistributing Excessive 50\% Responses in Elicited Probabilities.” Risk Analysis 22(4): 713-723.

Budescu, D.V. and Wallsten, T. S. 1987. Subjective Estimation of Precise and Vague Uncertainties. In G. Wright and P. Ayton Eds., Judgmental Forecasting. Wiley, pp. 63-81.

Budescu, D.V. and S. Weinberg and T.S. Wallsten. 1988. "Decisions Based on Numerically and Verbally Expressed Uncertainties.” Journal of Experimental Psychology: Human Perception and Performance 14: 281-294.

Budescu, D.V. and T.S. Wallsten. 1995. "Processing Linguistic Probabilities: General Principles and Empirical Evidence.” Psychology of Learning and Motivation 32: 275-318.

Camerer, C. and M. Weber. 1992. "Recent Developments in Modeling Preferences: Uncertainty and Ambiguity.” Journal of Risk and Uncertainty 5: 325-370.

Chene, G. and A. Beiser and R. Au and S.R. Preis and P.A. Wolf and C. Dufouil and S. Seshadri. 2015. "Gender and Incidence of Dementia in the Framingham Heart Study from Mid-Adult Life." Alzheimers Dementia 11(3): 310-320.

Dawber T.R. and G.F. Meadors F.E. Moore Jr. 1951. "Epidemiological Approaches to Heart Disease: The Framingham Study.” American Journal of Public Health Nations Health 41: 279-281.

Delavande, A. 2014. "Probabilistic Expectations in Developing Countries.” Annual Review of Economics 6: $1-20$.

Delavande, A. and J. Ganguli and F. Mengel. 2018. Measuring Ambiguity Attitudes and Their Impact on Behaviour in General Social Surveys. Working Paper, University of Essex

Dempster, A.P. 1968. “A Generalization of Bayesian Inference.” Journal of the Royal Statistical Society, Series B 30: 205-247. 
Dominitz, J. and C.F. Manski. 1997. "Perceptions of Economic Insecurity: Evidence From the Survey of Economic Expectations.” Public Opinion Quarterly 61: 261-287.

Dominitz, J. and C.F. Manski. 1999. “The Several Cultures of Research on Subjective Expectations.” In J.Smith and R.Willis, eds, Wealth, Work and Health: Innovations in Measurement in the Social Sciences. The University of Michigan Press, Chpt. 1, pp. 15-33.

Ellsberg, D. 1961. “Risk, Ambiguity, and the Savage Axioms.” The Quarterly Journal of Economics 75(4): 643-669.

Ertekin-Taner, N. 2007. “Genetics of Alzheimer’s Disease: A Centennial Review.” Neurologic Clinics 25(3): 611-667.

Finkelstein, A. and K. McGarry. 2006. "Multiple Dimensions of Private Information: Evidence from the Long-Term Care Insurance Market.” The American Economic Review 96(4): 938-958.

Fishman, E. 2017. "Risk of Developing Dementia at Older Ages in the United States.” Demography 54: 1897-1919.

Fischhoff, B. and W. Bruine de Bruin. 1999. Fifty-Fifty = 50\%? Journal of Behavioral Decision Making 12: $149-163$.

Gilboa, I. and M. Marinacci. 2013. “Ambiguity and the Bayesian Paradigm.” Advances in Economics and Econometrics: Theory and Applications Volume 1, Chapter 7, pp. 179-242.

Giustinelli, P. and C.F. Manski. 2018. "Survey Measures of Family Decision Processes for Econometric Analysis of Schooling Decisions.” Economic Inquiry 56(1): 81-99.

Giustinelli, P. and C.F. Manski and F. Molinari. 2019. Tail and Center Rounding of Probabilistic Expectations in the Health and Retirement Study, Working Paper.

Giustinelli, P. and N. Pavoni. 2017. "The Evolution of Awareness and Belief Ambiguity in the Process of High School Track Choice.” Review of Economic Dynamics 25, 93-120.

Heron, M. 2019. Deaths: Leading Causes for 2017. National Vital Statistics Reports 68(6).

Hudomiet, P. and R.J. Willis. 2013. "Estimating Second Order Probability Beliefs from Subjective Survival Data.” Decision Analysis 10(2): 152-170.

Hudomiet, P. and M.D. Hurd and S. Rohwedder. 2018. "Dementia Prevalence in the United States in 2000 and 2012: Estimates Based on a Nationally Representative Study.” Journal of Gerontology B Psychol Sci Soc Sci, 73(S1): S10-S19.

Hurd, M.D. 2009. Subjective Probabilities in Household Surveys. Annual Review of Economics 1, 543-562.

Hurd, M.D. and P. Martorell and A. Delavande and K.J. Mullen and K.M. Langa. 2013. "Monetary Costs of Dementia in the United States.” The New England Journal of Medicine 368, 1326-1334.

Juster, F.T. and R. Suzman. 1995. “An Overview of the Health and Retirement Study.” Journal of Human Resources 30: S7-56. 
Kannel W.B. and M. Feinleib and P.M. McNamara and R.J. Garrison and W.P. Castelli. 1979. "An Investigation of Coronary Heart Disease in Families. The Framingham Offspring Study.” American Journal of Epidemiology 110: 281-290.

Keynes, J.M. 1921. A Treatise on Probability. Macmillan \& Co.

Knight, F.H. 1921. "Risk, Uncertainty, and Profit.” in Hart, Schaffner, and Marx Prize Essays, 31. Houghton Mifflin, Boston and New York.

Kuznetsov, V.P. 1991. Interval Statistical Models. Radio i Svyaz Publications.

Kyburg, H.E. 1961. Probability and the Logic of Rational Belief. Wesleyan University Press.

Kyburg, H.E. 1983. Epistemology and Inference. University of Minnesota Press.

Kyburg, H.E. 1987. “Bayesian and Non-Bayesian Evidential Updating.” Artificial Intelligence 31: 271-293.

Kyburg, H.E., and M. Pittarelli. 1992. Set-based Bayesianism. Technical report, University of Rochester.

Kyburg, H.E. and C.M. Teng. 2001. Uncertain Inference, Cambridge University Press.

Levi, I. 1974. “On Indeterminate Probabilities.” Journal of Philosophy 71: 391-418.

Levi, I. 1980. The Enterprise of Knowledge. MIT Press.

Lillard, L. and R.J. Willis. 2001. Cognition and Wealth: The Importance of Probabilistic Thinking. Michigan Retirement Research Working Paper MRRC WP UM00-04, University of Michigan.

Manski, C.F. 2004. “Measuring Expectations.” Econometrica 72: 1329-1376.

Manski, C.F. 2007. Identification for Prediction and Decision. Harvard University Press.

Manski, C.F. 2018a. "Survey Measurement of Probabilistic Macroeconomic Expectations: Progress and Promise.” NBER Macroeconomics Annual 32: 411-471.

Manski, C.F. 2018b. "Credible Ecological Inference for Medical Decisions with Personalized Risk Assessment.” Quantitative Economics 9: 541-569.

Manski, C.F. and F. Molinari. 2010. "Rounding Probabilistic Expectations in Surveys.” Journal of Business and Economic Statistics 28(2), 219-231.

Morgan, M.G. and M. Henrion. 1990. Uncertainty: A Guide to Dealing with Uncertainty in Quantitative Risk and Policy Analysis. Cambridge University Press.

Morgan, M.G. and B. Fischhoff and A. Bostrom and C.J. Atman. 2001. Risk Communication: A Mental Model Approach. Cambridge University Press.

National Center for Health Statistics. 2013. Long-Term Care Services in the United States: 2013 Overview. National Health Care Statistics Reports 1.

National Institute on Aging (NIA). 2015. Alzheimer's Disease Genetics Fact Sheet. Accessed on June, 29 2019: https://www.nia.nih.gov/health/alzheimers-disease-genetics-fact-sheet 
Olson, M.L. and D.V. Budescu. 1997. "Patterns of Preference for Numerical and Verbal Probabilities." Journal of Behavioral Decision Making 10: 117-131.

Plassman, B.L. and K.M. Langa and G.G. Fisher and S.G. Heeringa and D.R. Weir and M.B. Ofstedal and R.B. Wallace. 2007. "Prevalence of Dementia in the United States: The aging, demographics, and memory study.” Neuroepidemiology 29: 125-132.

Schotter, A. and I. Trevino. 2014. "Belief Elicitation in the Laboratory.” Annual Review of Economics 6: 103-128.

Seshadri, S. and P.A. Wolf. 2007. "Lifetime Risk of Stroke and Dementia: Current Concepts, and Estimates from the Framingham Study.” Lancet Neurology 6: 1106-1114.

Shafer, G. 1976. A Mathematical Theory of Evidence. Princeton University Press.

van der Klaauw, W. 2012. "On the Use of Expectations Data in Estimating Structural Dynamic Models.” Journal of Labor Economics 30(3): 521-554.

Walley, P. (1991). Statistical Reasoning with Imprecise Probabilities. Vol. 42 of Monographs on Statistics and Applied Probability. Chapman and Hall.

Wallsten, T. S. 1974. "The Psychological Concept of Subjective Probability: A Measurement Theoretical View.” In C.A.S. Staël von Holstein Ed., The Concept of Probability in Psychological Experiments. Dordrecht, The Netherlands: Reidel, pp. 49-72.

Wallsten, T.S. 1990. “The Costs and Benefits of Vague Information.” In R. Hogarth Ed., Insights in Decision Making. A tribute to the late Hillel Einhorn. The University of Chicago Press, pp. 28-43.

Wallsten, T.S. and D.V. Budescu. 1983. "Encoding Subjective Probabilities: A Psychological and Psychometric Review.” Management Science 29: 151-173.

Wallsten, S.T. and B.H. Forsyth and D.V. Budescu. 1983. "Stability and Coherence of Health Experts' Upper and Lower Subjective Probabilities about Dose- Response Functions.” Organizational Behavior and Human Performance 31: 277-302.

Wallsten, T.S. and D.V. Budescu and R. Zwick. 1993a. "Comparing the Calibration and Coherence of Numerical and Verbal Probability Judgments.” Management Science, 39: 176-190.

Wallsten, T.S. and D.V. Budescu and R. Zwick and S.M. Kemp. 1993b. Preferences and Reasons for Communicating Probabilistic Information in Numerical or Verbal terms.” Bulletin of the Psychonomic Society 31: 135-138.

Weichselberger, K. 2000. "The Theory of Interval Probability as a Unifying Concept for Uncertainty.” International Journal of Approximate Reasoning 24(2-3): 149-170.

Woloshin, S. and L. Schwartz and S. Byram and B. Fischhoff and H.G. Welch. 2000. "A New Scale for Assessing Perceptions of Chance: A Validation Study.” Medical Decision Making 20: 298-307.

Zwick, R. and T.S. Wallsten. 1989. "Combining Stochastic and Linguistic Inexactness: Theory and Experimental Evaluation of Four Fuzzy Probability Models.” International Journal of Man Machine Studies, 30: 69-111. 
Figure 1. Relationship between Initial-Probe and Post-Probe Dementia Probabilities: Kernel Regressions

Kernel Regressions of Initial-Probe on Post-Probe Dementia Probabilities: Precise (top graph) vs. Imprecise (bottom graphs)
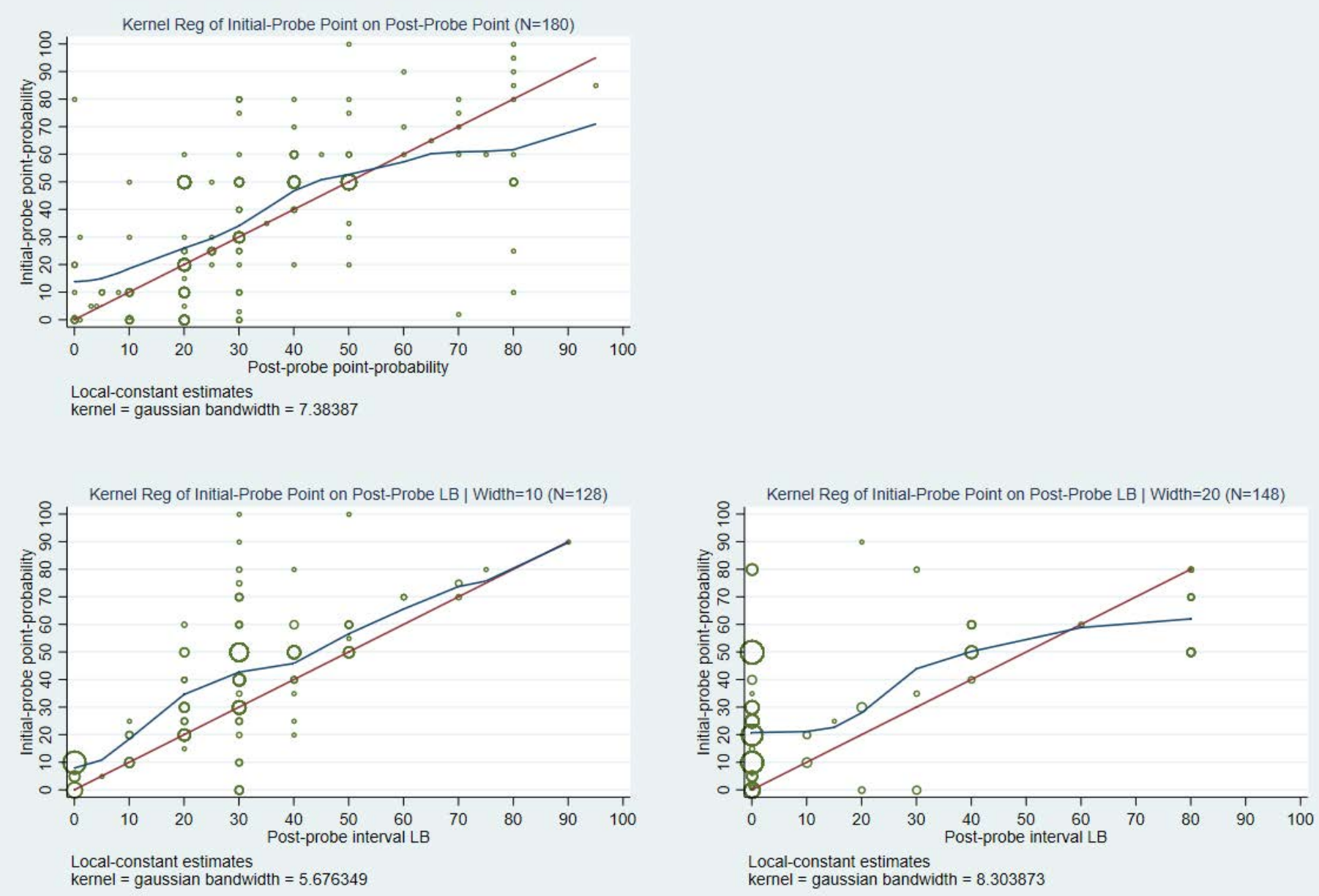

Note: Each graph shows: (i) univariate Kernel regression estimates of the conditional mean of initial-probe probability given post-probe probability (blue line), (ii) the 45-degree line (in red), and (iii) the scatterplot of initial-probe against post-probe probabilities (green dots). The size of each dot is proportional to the relative frequency of the corresponding observation. In the top-left graph, the conditioning variable is the post-probe point-probability, as the graph refers to the respondents who have precise dementia probabilities but report them in rounded form. In the bottom graphs, the conditioning variable is the lower bound of the post-probe probability interval, as these graphs refer to the respondents who have imprecise dementia probabilities (excluding those who gave spontaneous intervals). The respondents in the bottom-left graph have probability intervals of width 10, those in the bottom-right graph have probability intervals of width 20 . 


\section{TABLES}

Table 1. Classification of Responses to the Dementia Probability Question into Probabilistic

\begin{tabular}{|c|c|c|c|c|}
\hline \multicolumn{5}{|c|}{ Response Types } \\
\hline & $\begin{array}{c}\text { All } \\
\text { respondents }\end{array}$ & $\begin{array}{l}\text { Respondents } \\
\text { who gave } \\
\text { an initial } \\
\text { point response } \\
\text { of } 0\end{array}$ & $\begin{array}{l}\text { Respondents } \\
\text { who gave } \\
\text { an initial } \\
\text { point response } \\
\text { of } 50\end{array}$ & $\begin{array}{l}\text { Respondents } \\
\text { who gave } \\
\text { an initial } \\
\text { response other } \\
\text { than } 0 \text { or } 50\end{array}$ \\
\hline \% Exact Point (EX) & 34.82 & 73.30 & 27.90 & 27.08 \\
\hline \% Rounded Point (PR) & 14.34 & 8.25 & 23.61 & 13.24 \\
\hline \% Interval (IM) & $46.45^{*}$ & 15.53 & 47.64 & 53.92 \\
\hline \% Other & 4.38 & 2.91 & 0.86 & 5.76 \\
\hline $\mathrm{N}$ & 1,255 & 206 & 233 & 816 \\
\hline
\end{tabular}

Note: $\mathrm{N}=$ number of observations. ${ }^{*}$ The proportion of spontaneous interval probabilities is $6.5 \%$.

Table 2. Width of Interval Responses among Respondents with Imprecise Dementia Probability (IM)

\begin{tabular}{cccccc}
\hline & $\begin{array}{c}\text { Respondents } \\
\text { who gave } \\
\text { an initial } \\
\text { point } \\
\text { response }\end{array}$ & $\begin{array}{c}\text { Respondents } \\
\text { who gave } \\
\text { an initial } \\
\text { point } \\
\text { response } \\
\text { of } 0\end{array}$ & $\begin{array}{c}\text { Respondents } \\
\text { who gave } \\
\text { an initial } \\
\text { point } \\
\text { response } \\
\text { of } 50\end{array}$ & $\begin{array}{c}\text { Respondents } \\
\text { who gave } \\
\text { an initial } \\
\text { response } \\
\text { other than } \\
0 \text { or } 50\end{array}$ & $\begin{array}{c}\text { Respondents } \\
\text { who gave } \\
\text { an initial } \\
\text { interval } \\
\text { response }\end{array}$ \\
\hline $1^{\text {st decile }}$ & 10 & 10 & 10 & 10 & 10 \\
Median & 20 & 20 & 20 & 20 & 20 \\
$9^{\text {th decile }}$ & 80 & 80 & 70 & 80 & 80 \\
$\mathrm{~N}$ & 442 & 29 & 107 & 306 & 78 \\
\hline
\end{tabular}

Note: Shown statistics refer to respondents reporting a rounded point response followed by an interval (columns 14) or a spontaneous interval response followed by a "forced" point (column 5). For each respondent, the interval width is computed as the interval's upper bound minus the interval's lower bound. $\mathrm{N}=$ number of observations. 
Table 3. Within-Person Comparison of Initial Point Response and Post-Probe Point Response among Respondents Reporting Rounded/Approximated Dementia Probabilities (PR)

\begin{tabular}{|c|c|c|c|c|c|c|}
\hline $\begin{array}{l}\text { Post-Probe Point: } \\
\text { Pre-Probe Point: }\end{array}$ & $\begin{array}{c}\% 0,50 \\
\text { or } 100\end{array}$ & $\begin{array}{l}\% 25 \\
\text { or } 75\end{array}$ & $\begin{array}{l}\% \text { mult. } \\
\text { of } 10\end{array}$ & $\begin{array}{l}\% \text { mult. } \\
\text { of } 5\end{array}$ & $\begin{array}{l}\% \text { mult. } \\
\text { of } 1\end{array}$ & $\begin{array}{c}\text { Total } \\
\mathrm{N}\end{array}$ \\
\hline$\% 0,50$, or 100 & 12.78 & 0.56 & 27.22 & 0.00 & 0.56 & 74 \\
\hline$\% 25$ or 75 & 0.56 & 2.22 & 3.89 & 0.00 & 0.00 & 12 \\
\hline$\%$ multiple of 10 & 5.00 & 1.67 & 35.00 & 1.67 & 1.11 & 80 \\
\hline \% multiple of 5 & 0.56 & 0.00 & 2.22 & 1.67 & 1.11 & 10 \\
\hline$\%$ multiple of 1 & 0.56 & 0.00 & 1.67 & 0.00 & 0.00 & 4 \\
\hline Total $\mathrm{N}$ & 35 & 8 & 126 & 6 & 5 & 180 \\
\hline $\begin{array}{r}\text { \% granularity transitions: } \\
\text { finer } \\
\text { same } \\
\text { coarser }\end{array}$ & \multicolumn{6}{|c|}{$\begin{array}{l}36.12 \\
51.67 \\
12.21\end{array}$} \\
\hline$\%$ pre-probe $=$ post-probe & \multicolumn{6}{|c|}{$\begin{array}{l}12.21 \\
32.22\end{array}$} \\
\hline
\end{tabular}

Note: $\mathrm{N}=$ number of observations. $\% 0,50,100$ and $\% 25$ or 75 indicates a response equal to one of these numbers; \% mult. of 10 indicates a response that is a multiple of 10 other than $0,50,100$; \% mult. of 5 indicates a response that is a multiple of 5 other than 25, 75, or multiples of 10 ; \% mult. 1 indicates a response that is not a multiple of 5 .

Table 4. Within-Person Comparison of Initial Point Response and Post-Probe Interval Response among Respondents with Imprecise Dementia Probability (IM)

\begin{tabular}{|c|c|c|c|c|}
\hline & $\begin{array}{c}\text { Any } \\
\text { width }\end{array}$ & $(0,10]$ & $\begin{array}{l}\text { Width in: } \\
(10,20]\end{array}$ & $(20,100]$ \\
\hline \multicolumn{5}{|c|}{ Respondents who give first a point and then an interval } \\
\hline point is midpoint of the interval & 10.86 & 5.84 & 22.93 & 2.70 \\
\hline $\begin{array}{l}\text { point is inside the interval, } \\
\text { but not the midpoint }\end{array}$ & 58.14 & 54.74 & 45.86 & 74.32 \\
\hline $\begin{array}{l}\text { point is outside the interval, } \\
\text { within a } 5 \text { points distance }\end{array}$ & 4.30 & 4.38 & 5.09 & 3.38 \\
\hline $\begin{array}{l}\text { point is outside the interval, } \\
\text { within a } 6 \text {-to- } 10 \text { points distance }\end{array}$ & 11.54 & 18.98 & 6.37 & 10.14 \\
\hline $\begin{array}{l}\text { point is outside the interval, } \\
\text { a distance greater than } 10 \text { points }\end{array}$ & 15.16 & 16.06 & 19.75 & 9.46 \\
\hline $\mathrm{N}$ & 442 & 137 & 157 & 148 \\
\hline \multicolumn{5}{|c|}{ Respondents who give first an interval and then a point } \\
\hline point is midpoint of the interval & 16.67 & 18.53 & 43.75 & 2.86 \\
\hline $\begin{array}{l}\text { point is inside the interval, } \\
\text { but not the midpoint }\end{array}$ & 74.36 & 70.37 & 56.25 & 85.71 \\
\hline $\begin{array}{l}\text { point is outside the interval, } \\
\text { within a } 5 \text { points distance }\end{array}$ & 1.28 & 3.70 & 0 & 0 \\
\hline $\begin{array}{l}\text { point is outside the interval, } \\
\text { within a } 6 \text {-to- } 10 \text { points distance }\end{array}$ & 6.41 & 3.70 & 0 & 11.43 \\
\hline $\begin{array}{l}\text { point is outside the interval, } \\
\text { a distance greater than } 10 \text { points }\end{array}$ & 1.28 & 3.70 & 0 & 0 \\
\hline $\mathrm{N}$ & 78 & 27 & 16 & 35 \\
\hline
\end{tabular}

Note: $\mathrm{N}=$ number of observations. 
Table 5. Relationship between Initial-Probe and Post-Probe Dementia Probabilities:

Empirical Expectations of Initial-Probe Point $(y)$ Given Post-Probe Point or Interval $(x)$

Panel A. PR Group ( $x=$ post-probe point)

\begin{tabular}{|c|c|c|c|c|c|c|c|c|c|c|c|c|}
\hline $\mathrm{X}$ & 0 & 10 & 20 & 30 & 40 & 50 & 60 & 70 & 80 & 90 & 100 & \\
\hline $\mathrm{E}(y \mid x)$ & 16.38 & 11 & 24.57 & 35.79 & 52 & 52.22 & 73.33 & 57.4 & 62.08 & - & - & \\
\hline$[\mathrm{CI}]$ & $\begin{array}{c}{[0,} \\
69.56]\end{array}$ & $\begin{array}{c}{[0,} \\
41.80]\end{array}$ & $\begin{array}{c}{[0,} \\
61.92]\end{array}$ & $\begin{array}{c}{[0,} \\
78.08]\end{array}$ & $\begin{array}{l}\text { [28.55, } \\
75.45]\end{array}$ & $\begin{array}{l}\text { [23.41, } \\
81.03 \text { ] }\end{array}$ & $\begin{array}{c}\text { [43.39, } \\
100]\end{array}$ & {$[0,100]$} & $\begin{array}{c}{[6.57,} \\
100]\end{array}$ & & & \\
\hline $\mathrm{N}$ & 8 & 11 & 46 & 29 & 20 & 27 & 3 & 5 & 12 & 0 & 0 & \\
\hline \multicolumn{13}{|c|}{ Panel B. IM Group ( $x=$ interval LB) } \\
\hline $\mathrm{x}$ & 0 & 10 & 20 & 30 & 40 & 50 & 60 & 70 & 80 & & 90 & 100 \\
\hline \multicolumn{13}{|c|}{ Group with interval width = 10 ( $1^{\text {st }}$ decile $)$} \\
\hline $\mathrm{E}(y \mid x)$ & 7 & 15.83 & 29.74 & 43.33 & 46.43 & 59.44 & 70 & 72.5 & - & & 90 & - \\
\hline$[\mathrm{CI}]$ & {$[0,15.26]$} & $\begin{array}{l}{[2.80,} \\
28.86]\end{array}$ & $\begin{array}{l}\text { [4.97, } \\
54.50]\end{array}$ & $\begin{array}{c}\text { [5.66, } \\
81]\end{array}$ & $\begin{array}{l}{[17.81,} \\
75.05]\end{array}$ & $\begin{array}{l}\text { [28.28, } \\
90.61]\end{array}$ & & $\begin{array}{l}\text { [65.57, } \\
79.43]\end{array}$ & & & & \\
\hline $\mathrm{N}$ & 10 & 6 & 19 & 63 & 14 & 9 & 2 & 2 & 0 & & 1 & 0 \\
\hline \multicolumn{13}{|c|}{ Group with interval width $=20$ (median) } \\
\hline $\begin{array}{c}\mathrm{E}(y \mid x) \\
{[\mathrm{CI}]}\end{array}$ & $\begin{array}{c}20.77 \\
{[0,56.22]}\end{array}$ & $\begin{array}{c}15 \\
{[1.14,} \\
28.86]\end{array}$ & $\begin{array}{c}40 \\
{[0,100]}\end{array}$ & $\begin{array}{c}38.33 \\
{[0,100]}\end{array}$ & $\begin{array}{c}52.5 \\
{[38.64} \\
66.36] \\
\end{array}$ & - & 60 & - & $\begin{array}{c}62 \\
{[36.20,} \\
87.80]\end{array}$ & & - & - \\
\hline $\mathrm{N}$ & 120 & 2 & 3 & 3 & 8 & 0 & 1 & 0 & 10 & & 0 & 0 \\
\hline
\end{tabular}

Note: The confidence intervals are intersected with the $[0,100]$ interval. $\mathrm{N}=$ number of observations. 
Table 6. Initial and Post-Probe Dementia Probabilities by Probabilistic Response Type

\begin{tabular}{|c|c|c|c|c|c|c|}
\hline \multirow{2}{*}{$\begin{array}{l}\text { Response } \\
\text { distribution: }\end{array}$} & $\begin{array}{c}\text { Initial }=\text { Post } \\
\text { Probe }\end{array}$ & \multicolumn{2}{|c|}{ Initial } & \multicolumn{3}{|c|}{$\begin{array}{l}\text { Post } \\
\text { Probe }\end{array}$} \\
\hline & $\begin{array}{c}\text { Point-Prob. } \\
\text { in } \\
\text { EX } \\
\text { Group } \\
\end{array}$ & $\begin{array}{c}\text { Point-Prob. } \\
\text { in } \\
\text { PR } \\
\text { Group } \\
\end{array}$ & $\begin{array}{c}\text { Point-Prob. } \\
\text { in } \\
\text { IM } \\
\text { Group } \\
\end{array}$ & $\begin{array}{c}\text { Point-Prob. } \\
\text { in } \\
\text { PR } \\
\text { Group } \\
\end{array}$ & $\begin{array}{c}\text { LB } \\
\text { in } \\
\text { IM } \\
\text { Group }\end{array}$ & $\begin{array}{c}\text { UB } \\
\text { in } \\
\text { IM } \\
\text { Group } \\
\end{array}$ \\
\hline 0 & 34.55 & 9.44 & 5.49 & 4.44 & 50 & 0 \\
\hline 50 & 14.87 & 30.56 & 19.04 & 15 & 4.73 & 9.91 \\
\hline 100 & 1.60 & 1.11 & 0.51 & 0 & 0 & 16.22 \\
\hline Other value & 48.98 & 58.89 & 54.21 & 80.56 & 45.27 & 73.42 \\
\hline Interval & NA & NA & 13.89 & NA & NA & NA \\
\hline DK & NA & NA & 6.86 & NA & 0 & $0.45^{* *}$ \\
\hline $\mathrm{N}$ & 437 & 180 & 583 & 180 & $444 *$ & $444 *$ \\
\hline $1^{\text {st }}$ decile & 0 & 1 & 5 & 10 & 0 & 20 \\
\hline Median & 15 & 40 & 30 & 30 & 0 & 40 \\
\hline Mean & 25.46 & 37.21 & 34.77 & 33.65 & 15.56 & 45.84 \\
\hline $9^{\text {th }}$ decile & 70 & 70 & 70 & 70 & 40 & 100 \\
\hline $\mathrm{N}$ & 437 & 180 & $462 *$ & 180 & $444 *$ & $442 *$ \\
\hline
\end{tabular}

Note: Interval = spontaneous interval given. DK = Don't know. NA = not applicable. $\mathrm{N}=$ number of observations. The sample sizes do not add up to the totals shown in Table 1 because respondents with initial response of unclassified nature ("Other” in Table 1) have been omitted from this table. * These samples and the corresponding statistics do not include respondents giving a spontaneous interval. ** Don’t know, Refuse, or missing value. 
Table 7. Comparison of Means of the Dementia Probabilities Across Socio-Demographic Groups

\begin{tabular}{|c|c|c|c|c|c|c|}
\hline \multirow{3}{*}{$\begin{array}{r}\text { Group: } \\
\text { Outcome: } \\
\text { Estimate: }\end{array}$} & \multirow{2}{*}{\multicolumn{2}{|c|}{$\begin{array}{c}\text { EX + PR } \\
\text { Point Prob. }\end{array}$}} & \multicolumn{4}{|c|}{ IM } \\
\hline & & & \multicolumn{2}{|c|}{ Interval LB Prob. } & \multicolumn{2}{|c|}{ Interval UB Prob. } \\
\hline & Coef. & Mean & Coef. & Mean & Coef. & Mean \\
\hline \multicolumn{7}{|l|}{ Age } \\
\hline 59- (reference) & $\begin{array}{l}27.57 \\
(1.97)\end{array}$ & 27.57 & $\begin{array}{l}14.55 \\
(2.07)\end{array}$ & 14.55 & $\begin{array}{l}43.22 \\
(2.91)\end{array}$ & 43.22 \\
\hline $60-64$ & $\begin{array}{c}3.94 \\
(3.18)\end{array}$ & 31.51 & $\begin{array}{c}5.95 \\
(3.09)\end{array}$ & 20.50 & $\begin{array}{l}1.60 \\
(4.35)\end{array}$ & 44.82 \\
\hline $65-69$ & $\begin{array}{c}6.99 \\
(3.52)\end{array}$ & 34.56 & $\begin{array}{c}5.85 \\
(3.15)\end{array}$ & 20.40 & $\begin{array}{c}6.20 \\
(4.43)\end{array}$ & 49.42 \\
\hline $70-74$ & $\begin{array}{l}-0.07 \\
(3.38)\end{array}$ & 27.50 & $\begin{array}{l}-1.18 \\
(3.58)\end{array}$ & 13.37 & $\begin{array}{l}-1.26 \\
(5.03)\end{array}$ & 41.96 \\
\hline 75-79 & $\begin{array}{l}-3.98 \\
(3.74)\end{array}$ & 23.59 & $\begin{array}{c}1.53 \\
(3.26)\end{array}$ & 16.08 & $\begin{array}{c}6.56 \\
(4.57)\end{array}$ & 49.78 \\
\hline $80-84$ & $\begin{array}{c}0.62 \\
(4.69)\end{array}$ & 28.19 & $\begin{array}{l}-3.62 \\
(4.23)\end{array}$ & 10.93 & $\begin{array}{l}0.06 \\
(5.94)\end{array}$ & 43.28 \\
\hline $85+$ & $\begin{array}{l}-7.95 \\
(5.50)\end{array}$ & 19.92 & $\begin{array}{l}1.50 \\
(5.21)\end{array}$ & 16.05 & $\begin{array}{c}8.10 \\
(7.32)\end{array}$ & 51.32 \\
\hline $\begin{array}{l}\text { Gender } \\
\text { male (reference) }\end{array}$ & $\begin{array}{l}27.60 \\
(1.72)\end{array}$ & 27.60 & $\begin{array}{l}16.59 \\
(1.64)\end{array}$ & 16.59 & $\begin{array}{l}45.27 \\
(2.28)\end{array}$ & 45.27 \\
\hline female & $\begin{array}{l}1.48 \\
(2.21) \\
\end{array}$ & 29.08 & $\begin{array}{r}0.07 \\
(2.08)\end{array}$ & 16.66 & $\begin{array}{l}1.00 \\
(2.90)\end{array}$ & 46.27 \\
\hline $\begin{array}{l}\text { Race } \\
\text { white (reference) }\end{array}$ & $\begin{array}{l}30.64 \\
(1.27)\end{array}$ & 30.64 & $\begin{array}{l}17.08 \\
(1.15)\end{array}$ & 17.08 & $\begin{array}{l}45.19 \\
(1.60)\end{array}$ & 45.19 \\
\hline black & $\begin{array}{c}-8.54 \\
(2.71)\end{array}$ & 22.10 & $\begin{array}{l}-4.21 \\
(2.92)\end{array}$ & 12.21 & $\begin{array}{c}9.94 \\
(5.12)\end{array}$ & 55.13 \\
\hline other & $\begin{array}{r}-5.06 \\
(3.87) \\
\end{array}$ & 25.58 & $\begin{array}{c}1.81 \\
(3.67)\end{array}$ & 18.89 & $\begin{array}{c}-0.93 \\
(4.06) \\
\end{array}$ & 44.26 \\
\hline \multicolumn{7}{|l|}{ Education } \\
\hline $\begin{array}{l}\text { no diploma } \\
\text { (reference) }\end{array}$ & $\begin{array}{l}19.39 \\
(2.67)\end{array}$ & 19.39 & $\begin{array}{l}15.49 \\
(2.66)\end{array}$ & 15.49 & $\begin{array}{l}47.05 \\
(3.72)\end{array}$ & 47.05 \\
\hline high school & $\begin{array}{l}11.87 \\
(3.04)\end{array}$ & 31.26 & $\begin{array}{l}-0.48 \\
(2.99)\end{array}$ & 15.01 & $\begin{array}{l}-4.43 \\
(4.20)\end{array}$ & 42.62 \\
\hline some college & $\begin{array}{l}13.78 \\
(4.60)\end{array}$ & 33.17 & $\begin{array}{c}7.98 \\
(4.36)\end{array}$ & 23.47 & $\begin{array}{c}4.62 \\
(6.11)\end{array}$ & 51.67 \\
\hline bachelor & $\begin{array}{c}9.41 \\
(3.89)\end{array}$ & 28.80 & $\begin{array}{l}7.17 \\
(3.74)\end{array}$ & 22.66 & $\begin{array}{c}5.85 \\
(5.25)\end{array}$ & 52.90 \\
\hline graduate & $\begin{array}{r}3.97 \\
(4.54) \\
\end{array}$ & 23.36 & $\begin{array}{l}-2.91 \\
(4.08) \\
\end{array}$ & 12.58 & $\begin{array}{l}-0.49 \\
(5.72) \\
\end{array}$ & 46.56 \\
\hline $\mathrm{N}$ & 591 & & & & & \\
\hline
\end{tabular}

Note: Standard errors in parenthesis. $\mathrm{N}=$ number of observations. 


\section{Supplementary Appendix to Section 3}

\section{Survey Structure and Classification of Respondents’ Probabilities}

Figure S1. Survey Structure and Classification of Respondents’ Probabilities

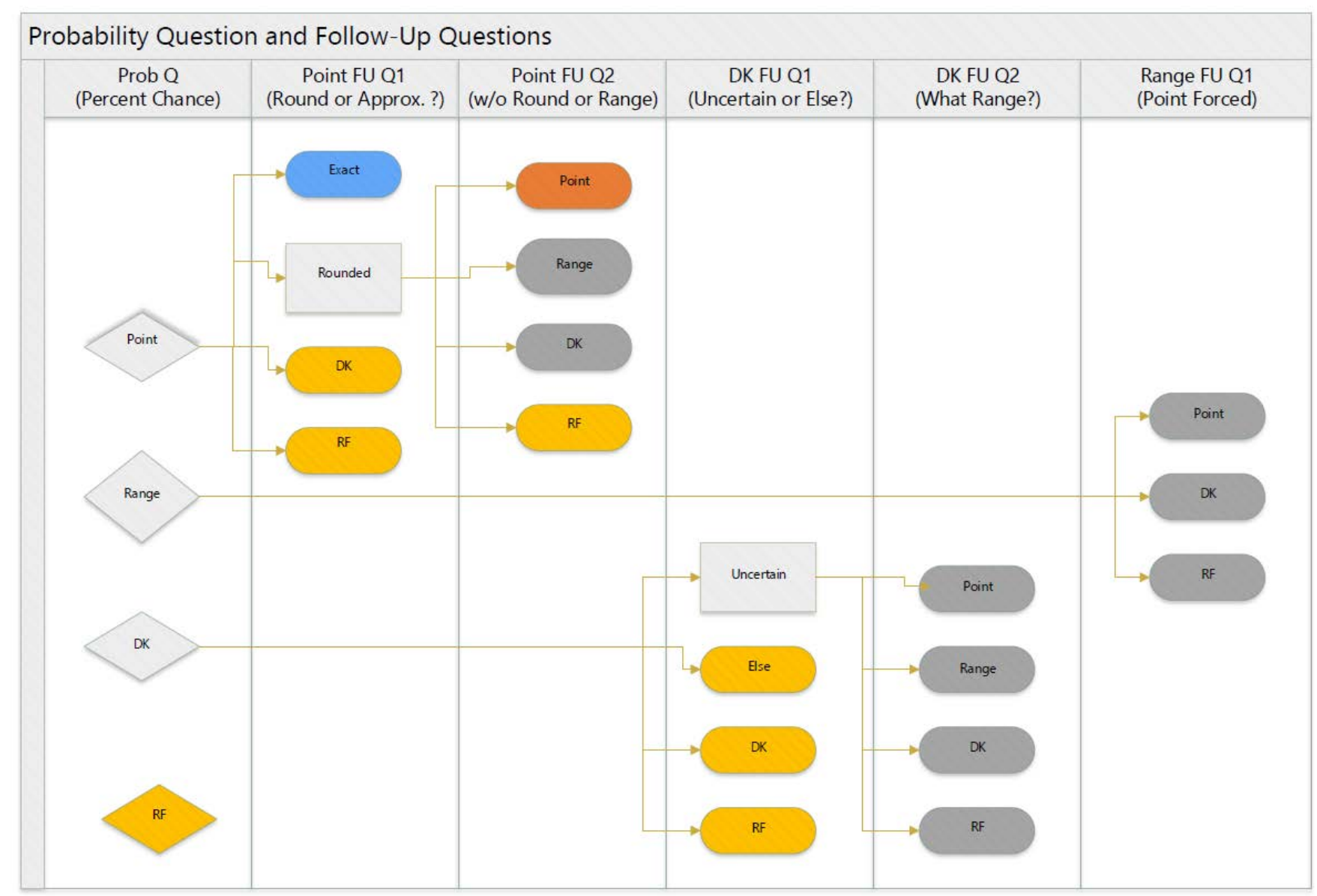

Note: Figure 1 displays the feasible survey paths following any of the four expectations questions asked in the module (unconditional LTC, unconditional dementia, conditional LTC given no dementia, and conditional LTC given dementia). The displayed paths are mutually exclusive across alternative answers to the initial expectation question, listed in the first panel to the left (from top to bottom: "Point”, “Range”, "Don’t know”, and "Refuse”). For each expectation question, we use the answers to the corresponding follow-up questions to classify respondents' probabilities into one of four mutually exclusive and exhaustive categories. The follow-up questions are listed at the top of the panels from the second to the left to the sixth and last panel to the right. The probabilities of respondents who gave an exact point response to the initial expectation question are classified as "Exact" (EX). The probabilities of respondents who gave a rounded point response followed by an unrounded point response are classified as "Precise" (PR). The probabilities of respondents who gave a rounded point response followed by an interval or a DK response are classified as "Imprecise" (IM); this category includes spontaneous interval responses and DK responses by respondents who felt unsure about the chances. The probabilities of all remaining respondents are labelled as "Other”. 


\section{Supplementary Appendix to Section 4}

\section{Heterogeneity in Probabilistic Response Type and Extent of Probability Imprecision of Dementia Probabilities Across Respondents' Characteristics}

In Tables S1 and S2 we investigate heterogeneity in probabilistic response types and in the amount of imprecision in subjective dementia probabilities across respondents.

Specifically, in Table S1 we use a multinomial probit regression to predict classification of respondents' unconditional probabilities of dementia status into: exact point-probability (EX), rounded/approximated but otherwise precise point-probability (PR), imprecise interval-probability (IM), and “other," as a function of respondents' observable characteristics. The dependent variable, $y$, takes values in $\{1,2,3,4\}$, where: $1=\mathrm{EX}$ (the reference outcome), $2=\mathrm{PR}, 3=\mathrm{IM}$, and $4=$ Other. The vector of covariates, $X$, includes dummy variables for age (“Less than 59” omitted), gender (“Male” omitted), race ("White" omitted), and education ("Less than high school” omitted). In a second specification, we add a measure of cognition to the vector of covariates.

In Table S2, we further estimate best linear predictors under square loss of the width of interval dementia probabilities conditional on the same vector of covariates among respondents with imprecise dementia probabilities.

In Table S1, we find that older respondents are systematically and statistically significantly more likely than younger respondents to report rounded or approximated dementia probabilities, to hold interval probabilities, and to give a response we could not classify (i.e., classified as “other”).

Black respondents are statistically significantly less likely to report rounded/approximated dementia probabilities as well as to hold imprecise probabilities, whereas respondents other than white or black, (including Hispanic, Asian, and Pacific Islander), are statistically significantly more likely to have their response to the dementia probability question classified as "other.”

More educated respondents are less likely to report a rounded or approximated dementia probability, (statistically significant only for the group with a high school diploma relative to the omitted group without a diploma), and less likely to give a dementia probability report we could not classify, (statistically significant only for the group with a graduate degree). On the other hand, more educated respondents seem more likely to hold imprecise probabilities, although this association is not statistically significant.

We also find no statistically significant associations between dementia probabilistic response type and respondents' gender and between dementia probabilistic response type and respondents’ cognitive ability.

In Table S2, we find that respondents of race other than white or black tend to give wider probability intervals (statistically significant only in the subsample of respondents who gave a point followed by an interval), whereas black respondents tend to give narrower probability intervals (only in the subsample of 
respondents who gave spontaneous intervals). We additionally find that respondents with a cognitive score in the top tercile of the score distribution tend to give wider intervals than those reported by respondents with a cognitive score in the middle tercile of the score distribution (nearly 7 percent points larger on average).

While being female appears to be positively associated with interval width and education appears to be negatively associated with interval width, these correlations are not statistically different from zero. The signs of the associations between the age dummies and the interval width are mixed, but none of these associations are statistically significant.

\section{Supplementary Appendix to Section 5}

\section{Distribution of Initial-Probe and Post-Probe Responses to the Dementia Probability Question by Probabilistic Response Type}

Table S3 shows the empirical distributions of initial-probe and post-probe reports of dementia probability in the three main sub-samples of respondents: (i) those holding precise probabilities and reporting them as exact numbers (EX), (ii) those holding precise probabilities and reporting them as rounded or approximated numbers (PR), and (iii) those with imprecise probabilities (IM). Relative to Table 3 of the main text, Table S3 reports these distributions at a greater level of granularity.

The majority of respondents perceive developing dementia as uncertain but not highly likely. Between $50 \%$ and $96 \%$ of respondents (depending on the column) assigns a non-corner probability to the event that they will develop dementia in the future. The large majority of responses are strictly below 50 percent in all columns, with a sample median ranging between 0 and 40 percent across columns.

The empirical response distributions in Table S3 feature the usual heaping at multiples of 10 and 5 percent, extensively documented by the subjective expectations literature. Less than 3\% of responses to the dementia probability questions are multiples of 1 percent that are not multiples of 5 or 10 percent. In Section 4.2 of the text, we investigate the granularity of initial-probe and post-probe reports of dementia probability in greater detail and document that precise-probability respondents tend to give weakly more refined post-probe responses than initial-probe responses.

\section{Heterogeneity in Perceived Dementia Risk across Respondents' Characteristics}

In Table S4, we report estimates of multivariate mean linear regressions of dementia probability conditional on the usual vector of covariates, separately for respondents holding precise dementia 
probabilities (in Column 1-2) and for those respondents with imprecise dementia probabilities (in Columns 3-6).

For respondents with precise probabilities, the outcome variable is their post-probe point probability of dementia. Column 1 reports OLS estimates for a basic specification including age, gender, race, and education dummies. Column 2 reports OLS estimates for a specification which additionally includes cognition dummies among the covariates vector.

For respondents with imprecise probabilities, we estimate two regression models. The first uses the interval LB as an outcome variable and the usual set of covariates (basic in Column 3 and with cognition in Column 4). The second uses the whole probability interval as a dependent variable and the usual set of covariates (basic in Column 5 and with cognition in Column 6). Note that the latter two regressions condition on imprecise-probability respondents with interval width equal to 10 percent.

Thus, as in Table 7 of the main text, Columns 5 and 6 show set-BLP estimates of the subjective interval probability on the covariates. In this case, the resulting best linear predictor's parameter vector is partially identified. We report estimates of the identification regions along with confidence intervals obtained using the method proposed by Beresteanu and Molinari (2008) and the Stata package by Beresteanu et al. (2010).

When conditioning on the whole vector of covariates, we find that the negative correlation between the subjective probability of dementia and the black dummy and the positive correlation between the subjective probability of dementia and the middle education dummies persist in the precise-probability sample (Columns 1-2). The positive correlation between the subjective dementia probability and the age dummies for younger groups persists only for the 65-69 category (in Column 1) and vanishes as the cognition dummies are added to the regression specification (in Columns 2). The negative correlation for the oldest group (85+) does persist conditional on the other covariates (Columns 1-2).

In the imprecise-probability sub-sample, the only observed statistically significant association is between the LB probability and the young age dummies (for the 60-64 and the 65-69 categories in Columns 3-4). Finally, in Columns 5-6 all estimated identification regions (as well as their confidence sets) include the zero. Thus, the sign of the correlation is unidentified for all conditioning variables. 


\section{References}

Beresteanu, A. and F. Molinari. 2008. “Asymptotic Properties for a Class of Partially Identified Models.” Econometrica 76(4), 763-814.

Beresteanu, A. and F. Molinari and D. Steeg Morris. 2010. "Asymptotics for Partially Identified Models in STATA.” Computer program available at: https://molinari.economics.cornell.edu/programs.html 


\section{TABLES}

Table S1. Predictors of Probabilistic Response Type for the Probability of Dementia: Estimated Coefficients of a Multinomial Probit Given Observed Covariates

\begin{tabular}{|c|c|c|c|c|c|c|}
\hline \multirow{2}{*}{$\begin{array}{l}\text { Base outcome: } \\
\mathrm{EX} \\
(y=1)\end{array}$} & \multicolumn{3}{|c|}{ Basic Specification } & \multicolumn{3}{|c|}{ Specification with Cognition } \\
\hline & $\begin{array}{c}\text { PR } \\
(y=2)\end{array}$ & $\begin{array}{c}\text { IM } \\
(y=3)\end{array}$ & $\begin{array}{l}\text { Other } \\
(y=4)\end{array}$ & $\begin{array}{c}\text { PR } \\
(y=2)\end{array}$ & $\begin{array}{c}\text { IM } \\
(y=3)\end{array}$ & $\begin{array}{l}\text { Other } \\
(y=4)\end{array}$ \\
\hline \multicolumn{7}{|l|}{ Age (“59-” omitted) } \\
\hline $60-64$ & $\begin{array}{c}0.25 \\
(0.19)\end{array}$ & $\begin{array}{c}0.22 \\
(0.16)\end{array}$ & $\begin{array}{c}0.22 \\
(0.33)\end{array}$ & $\begin{array}{c}0.36 \\
(0.24)\end{array}$ & $\begin{array}{c}0.35 \\
(0.19)\end{array}$ & $\begin{array}{c}0.12 \\
(0.42)\end{array}$ \\
\hline $65-69$ & $\begin{array}{c}0.44 \\
(0.21)\end{array}$ & $\begin{array}{c}0.37 \\
(0.17)\end{array}$ & $\begin{array}{c}0.96 \\
(0.31)\end{array}$ & $\begin{array}{c}0.66 \\
(0.36)\end{array}$ & $\begin{array}{c}0.66 \\
(0.29)\end{array}$ & $\begin{array}{c}0.78 \\
(0.57)\end{array}$ \\
\hline $70-74$ & $\begin{array}{c}0.85 \\
(0.21)\end{array}$ & $\begin{array}{c}0.25 \\
(0.18)\end{array}$ & $\begin{array}{c}1.08 \\
(0.32)\end{array}$ & $\begin{array}{c}1.07 \\
(0.36)\end{array}$ & $\begin{array}{c}0.53 \\
(0.30)\end{array}$ & $\begin{array}{c}0.90 \\
(0.57)\end{array}$ \\
\hline $75-79$ & $\begin{array}{c}0.16 \\
(0.23)\end{array}$ & $\begin{array}{c}0.37 \\
(0.18)\end{array}$ & $\begin{array}{c}0.75 \\
(0.33)\end{array}$ & $\begin{array}{c}0.39 \\
(0.37)\end{array}$ & $\begin{array}{c}0.65 \\
(0.30)\end{array}$ & $\begin{array}{c}0.59 \\
(0.58)\end{array}$ \\
\hline $80-84$ & $\begin{array}{c}0.61 \\
(0.28)\end{array}$ & $\begin{array}{c}0.46 \\
(0.23)\end{array}$ & $\begin{array}{c}1.20 \\
(0.38)\end{array}$ & $\begin{array}{c}0.83 \\
(0.41)\end{array}$ & $\begin{array}{c}0.75 \\
(0.33)\end{array}$ & $\begin{array}{c}1.01 \\
(0.61)\end{array}$ \\
\hline $85^{+}$ & $\begin{array}{c}0.54 \\
(0.32)\end{array}$ & $\begin{array}{c}0.28 \\
(0.27)\end{array}$ & $\begin{array}{c}1.93 \\
(0.37)\end{array}$ & $\begin{array}{c}0.75 \\
(0.43)\end{array}$ & $\begin{array}{c}0.57 \\
(0.35)\end{array}$ & $\begin{array}{c}1.72 \\
(0.59)\end{array}$ \\
\hline \multicolumn{7}{|l|}{ Gender (“Male” omitted) } \\
\hline Female & $\begin{array}{l}-0.12 \\
(0.13)\end{array}$ & $\begin{array}{c}0.07 \\
(0.11)\end{array}$ & $\begin{array}{l}-0.20 \\
(0.18)\end{array}$ & $\begin{array}{l}-0.11 \\
(0.13)\end{array}$ & $\begin{array}{c}0.07 \\
(0.11)\end{array}$ & $\begin{array}{c}-0.18 \\
(0.18)\end{array}$ \\
\hline \multicolumn{7}{|l|}{ Race (“White” omitted) } \\
\hline Black & $\begin{array}{l}-0.34 \\
(0.18)\end{array}$ & $\begin{array}{l}-0.37 \\
(0.14)\end{array}$ & $\begin{array}{c}0.20 \\
(0.23)\end{array}$ & $\begin{array}{l}-0.35 \\
(0.18)\end{array}$ & $\begin{array}{l}-0.37 \\
(0.14)\end{array}$ & $\begin{array}{c}0.18 \\
(0.23)\end{array}$ \\
\hline Other & $\begin{array}{c}0.43 \\
(0.23)\end{array}$ & $\begin{array}{c}0.16 \\
(0.20)\end{array}$ & $\begin{array}{c}0.77 \\
(0.31)\end{array}$ & $\begin{array}{c}0.43 \\
(0.23)\end{array}$ & $\begin{array}{c}0.17 \\
(0.20)\end{array}$ & $\begin{array}{c}0.75 \\
(0.31)\end{array}$ \\
\hline \multicolumn{7}{|l|}{$\begin{array}{l}\text { Educ ("No diploma” } \\
\text { omitted) }\end{array}$} \\
\hline High school & $\begin{array}{l}-0.33 \\
(0.18)\end{array}$ & $\begin{array}{c}0.03 \\
(0.16)\end{array}$ & $\begin{array}{l}-0.29 \\
(0.24)\end{array}$ & $\begin{array}{l}-0.31 \\
(0.19)\end{array}$ & $\begin{array}{c}0.02 \\
(0.16)\end{array}$ & $\begin{array}{l}-0.25 \\
(0.24\end{array}$ \\
\hline Some college & $\begin{array}{l}-0.19 \\
(0.28)\end{array}$ & $\begin{array}{c}0.18 \\
(0.23)\end{array}$ & $\begin{array}{c}0.16 \\
(0.36)\end{array}$ & $\begin{array}{l}-0.18 \\
(0.28)\end{array}$ & $\begin{array}{c}0.17 \\
(0.23)\end{array}$ & $\begin{array}{c}0.20 \\
(0.36)\end{array}$ \\
\hline Bachelor & $\begin{array}{l}-0.21 \\
(0.23)\end{array}$ & $\begin{array}{c}0.04 \\
(0.20)\end{array}$ & $\begin{array}{l}-0.42 \\
(0.33)\end{array}$ & $\begin{array}{l}-0.19 \\
(0.24)\end{array}$ & $\begin{array}{c}0.02 \\
(0.21)\end{array}$ & $\begin{array}{l}-0.37 \\
(0.33)\end{array}$ \\
\hline Graduate & $\begin{array}{l}-0.32 \\
(0.27)\end{array}$ & $\begin{array}{c}0.28 \\
(0.23)\end{array}$ & $\begin{array}{l}-1.13 \\
(0.57)\end{array}$ & $\begin{array}{l}-0.29 \\
(0.28)\end{array}$ & $\begin{array}{c}0.26 \\
(0.23)\end{array}$ & $\begin{array}{l}-1.05 \\
(0.57)\end{array}$ \\
\hline \multicolumn{7}{|l|}{$\begin{array}{l}\text { Cognition (Mid tercile } \\
\text { omitted) }\end{array}$} \\
\hline Bottom tercile & & & & $\begin{array}{c}0.19 \\
(0.31)\end{array}$ & $\begin{array}{c}0.33 \\
(0.25)\end{array}$ & $\begin{array}{l}-0.27 \\
(0.48)\end{array}$ \\
\hline Top tercile & & & & $\begin{array}{l}-0.07 \\
(0.17)\end{array}$ & $\begin{array}{c}0.08 \\
(0.14)\end{array}$ & $\begin{array}{l}-0.19 \\
(0.21)\end{array}$ \\
\hline Constant & $\begin{array}{l}-0.64 \\
(0.23)\end{array}$ & $\begin{array}{l}-0.02 \\
(0.19)\end{array}$ & $\begin{array}{l}-1.83 \\
(0.34)\end{array}$ & $\begin{array}{l}-0.85 \\
(0.38) \\
\end{array}$ & $\begin{array}{l}-0.34 \\
(0.32) \\
\end{array}$ & $\begin{array}{l}-1.59 \\
(0.59) \\
\end{array}$ \\
\hline $\mathrm{N}$ & & 1,214 & & & 1,213 & \\
\hline Log-likelihood & & 334.097 & & & -1330.982 & \\
\hline
\end{tabular}

Note: Standard errors in parentheses. $\mathrm{N}=$ number of observations. 
Table S2. Predictors of Interval Width for Respondents with Imprecise Dementia Probabilities (IM)

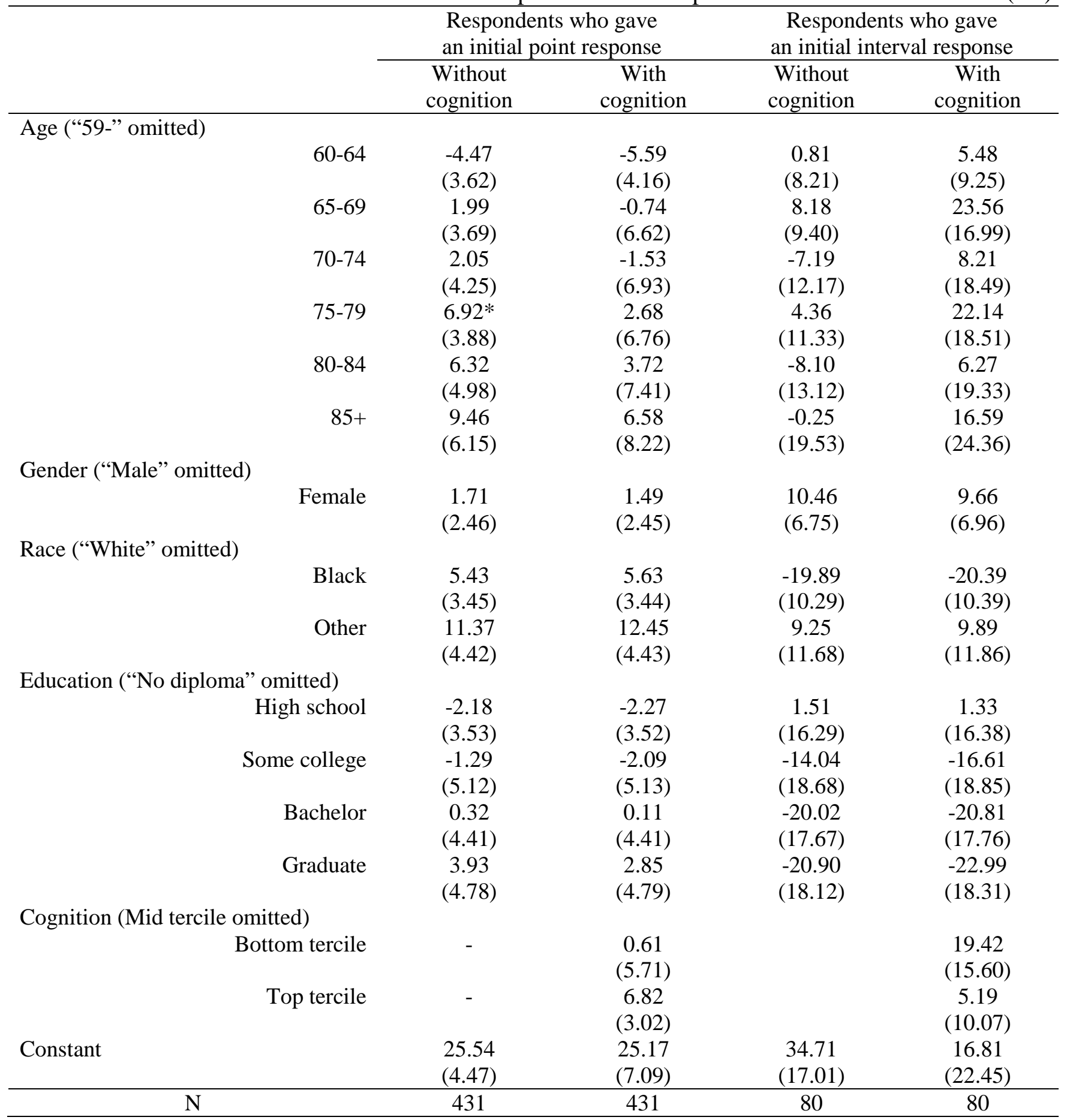

Note: Standard errors in parentheses. $\mathrm{N}$ = number of observations. 
Table S3. Initial-Probe and Post-Probe Response Distributions to the Dementia Probability Question by Probabilistic Response Type

\begin{tabular}{|c|c|c|c|c|c|c|}
\hline \multirow{3}{*}{$\begin{array}{c}\text { Response } \\
\text { distribution: } \\
0\end{array}$} & \multirow{2}{*}{$\begin{array}{c}\text { Initial=Post Probe } \\
\text { Point-Prob. } \\
\text { in EX } \\
\text { Group }\end{array}$} & \multicolumn{2}{|c|}{ Initial Probe } & \multicolumn{3}{|c|}{ Post Probe } \\
\hline & & $\begin{array}{c}\text { Point-Prob. } \\
\text { in PR } \\
\text { Group }\end{array}$ & $\begin{array}{c}\text { Point-Prob. } \\
\text { in IM } \\
\text { Group }\end{array}$ & $\begin{array}{c}\text { Point-Prob. } \\
\text { in PR } \\
\text { Group }\end{array}$ & $\begin{array}{c}\text { LB } \\
\text { in IM } \\
\text { Group }\end{array}$ & $\begin{array}{l}\text { UB } \\
\text { in IM } \\
\text { Group }\end{array}$ \\
\hline & 34.55 & 9.44 & 5.49 & 4.44 & 50 & 0 \\
\hline $1-4$ & 1.60 & 2.22 & 1.04 & 2.22 & 0.68 & 0 \\
\hline 5 & 4.12 & 1.67 & 2.06 & 1.11 & 0.90 & 1.35 \\
\hline $6-9$ & 0.23 & 0 & 0.17 & 0.56 & 0 & 0 \\
\hline 10 & 7.78 & 10.56 & 11.32 & 6.11 & 3.15 & 2.48 \\
\hline $11-14$ & 0.23 & 0 & 0 & 0 & 0 & 0 \\
\hline 15 & 1.60 & 0.56 & 0.69 & 0 & 0.44 & 1.13 \\
\hline $16-19$ & 0 & 0 & 0 & 0 & 0 & 0 \\
\hline 20 & 8.47 & 10 & 10.29 & 25.55 & 10.14 & 28.60 \\
\hline $21-24$ & 0.23 & 0 & 0 & 0 & 0 & 0 \\
\hline 25 & 2.75 & 5 & 4.46 & 3.88 & 0.90 & 1.13 \\
\hline $26-29$ & 0 & 0 & 0 & 0 & 0 & 0 \\
\hline 30 & 3.89 & 7.78 & 6.35 & 16.10 & 18.47 & 9.91 \\
\hline $31-34$ & 0.23 & 0 & 0 & 0 & 0 & 0 \\
\hline 35 & 0.69 & 1.11 & 0.69 & 0.56 & 0 & 0.23 \\
\hline $36-39$ & 0 & 0 & 0 & 0 & 0 & 0 \\
\hline 40 & 4.58 & 2.22 & 4.63 & 11.11 & 5.63 & 17.33 \\
\hline $41-44$ & 0 & 0 & 0 & 0 & 0 & 0 \\
\hline 45 & 0.23 & 0 & 0.34 & 0.56 & 0 & 0 \\
\hline $46-49$ & 0 & 0 & 0 & 0 & 0 & 0 \\
\hline 50 & 14.87 & 30.56 & 19.04 & 15 & 4.73 & 9.91 \\
\hline 51-54 & 0 & 0 & 0 & 0 & 0 & 0 \\
\hline 55 & 0.23 & 0 & 0.34 & 0 & 0 & 0 \\
\hline $56-59$ & 0 & 0 & 0 & 0 & 0 & 0 \\
\hline 60 & 1.60 & 7.21 & 2.74 & 1.67 & 0.90 & 4.50 \\
\hline $61-64$ & 0 & 0 & 0 & 0 & 0 & 0 \\
\hline 65 & 0.46 & 0.56 & 0.17 & 0.56 & 0 & 0 \\
\hline 66-69 & 0 & 0 & 0 & 0 & 0 & 0 \\
\hline 70 & 2.75 & 1.67 & 3.09 & 2.78 & 1.13 & 1.13 \\
\hline 71-74 & 0 & 0 & 0 & 0 & 0 & 0 \\
\hline 75 & 1.37 & 1.67 & 1.20 & 0.56 & 0.23 & 0.45 \\
\hline 76-79 & 0.23 & 0 & 0 & 0 & 0 & 0 \\
\hline 80 & 4.12 & 3.88 & 3.43 & 6.67 & 2.25 & 4.95 \\
\hline 81-84 & 0 & 0 & 0 & 0 & 0 & 0 \\
\hline 85 & 0 & 1.11 & 0.17 & 0 & 0 & 0.23 \\
\hline 86-89 & 0 & 0 & 0 & 0 & 0 & 0 \\
\hline 90 & 1.36 & 1.11 & 0.86 & 0 & 0.23 & 0 \\
\hline 91-94 & 0 & 0 & 0 & 0 & 0 & 0 \\
\hline 95 & 0.23 & 0.56 & 0.17 & 0.56 & 0.23 & 0 \\
\hline 96-99 & 0 & 0 & 0 & 0 & 0 & 0 \\
\hline 100 & 1.60 & 1.11 & 0.51 & 0 & 0 & 16.22 \\
\hline Interval & NA & NA & 13.89 & NA & NA & NA \\
\hline $\begin{array}{l}\text { NR (DK or } \\
\text { Refuse) }\end{array}$ & NA & NA & 6.86 & 0 & 0 & 0.45 \\
\hline $\mathrm{N}$ & 437 & 180 & 583 & 180 & 444 & 444 \\
\hline
\end{tabular}

Note: $\mathrm{N}$ = number of observations. 
Table S4. Best Linear Prediction of Dementia Probabilities Given Covariates

\begin{tabular}{|c|c|c|c|c|c|c|}
\hline \multirow{2}{*}{$\begin{array}{r}\text { Group: } \\
\text { Outcome: }\end{array}$} & \multicolumn{2}{|c|}{$\mathrm{EX}+\mathrm{PR}$} & \multicolumn{4}{|c|}{ IM } \\
\hline & $\begin{array}{l}\text { Point } \\
\text { Prob. }\end{array}$ & $\begin{array}{l}\text { Point } \\
\text { Prob. }\end{array}$ & $\begin{array}{c}\text { Interval } \\
\text { LB } \\
\text { Prob. }\end{array}$ & $\begin{array}{c}\text { Interval } \\
\text { LB } \\
\text { Prob. }\end{array}$ & $\begin{array}{c}\text { Interval } \\
\text { given } \\
\text { Width=10 }\end{array}$ & $\begin{array}{c}\text { Interval } \\
\text { given } \\
\text { Width=10 }\end{array}$ \\
\hline Age (“59-” omitted) & & & & & & \\
\hline 60-64 & $\begin{array}{c}3.98 \\
(3.15)\end{array}$ & $\begin{array}{c}3.34 \\
(3.83)\end{array}$ & $\begin{array}{c}6.24 \\
(3.09)\end{array}$ & $\begin{array}{c}7.98 \\
(3.58)\end{array}$ & $\begin{array}{c}-3.08,21.97 \\
(-11.32,30.21)\end{array}$ & $\begin{array}{c}-4.24,22.79 \\
(-14.44,32.99)\end{array}$ \\
\hline $65-69$ & $\begin{array}{c}6.14 \\
(3.49)\end{array}$ & $\begin{array}{c}3.87 \\
(5.86)\end{array}$ & $\begin{array}{c}6.05 \\
(3.17)\end{array}$ & $\begin{array}{l}10.52 \\
(5.68)\end{array}$ & $\begin{array}{c}0.48,24.24 \\
(-7.90,32.61)\end{array}$ & $\begin{array}{c}-9.86,34.85 \\
(-23.34,48.33)\end{array}$ \\
\hline $70-74$ & $\begin{array}{l}-0.71 \\
(3.41)\end{array}$ & $\begin{array}{l}-3.04 \\
(5.83)\end{array}$ & $\begin{array}{l}-0.63 \\
(3.64)\end{array}$ & $\begin{array}{c}4.26 \\
(5.96)\end{array}$ & $\begin{array}{c}-16.86,9.54 \\
(-25.75,18.43)\end{array}$ & $\begin{array}{c}-28.19,18.93 \\
(-42.25,32.99)\end{array}$ \\
\hline $75-79$ & $\begin{array}{l}-3.87 \\
(3.74)\end{array}$ & $\begin{array}{l}-5.99 \\
(5.96)\end{array}$ & $\begin{array}{c}1.42 \\
(3.32)\end{array}$ & $\begin{array}{c}6.67 \\
(5.81)\end{array}$ & $\begin{array}{c}-8.06,18.64 \\
(-15.68,26.26)\end{array}$ & $\begin{array}{c}-18.76,28.45 \\
(-32.23,41.91)\end{array}$ \\
\hline $80-84$ & $\begin{array}{l}-0.28 \\
(4.72)\end{array}$ & $\begin{array}{l}-2.61 \\
(6.69)\end{array}$ & $\begin{array}{l}-3.72 \\
(4.27)\end{array}$ & $\begin{array}{c}0.69 \\
(6.36)\end{array}$ & $\begin{array}{c}-13.24,14.28 \\
(-21.50,22.54)\end{array}$ & $\begin{array}{c}-22.83,23.81 \\
(-36.32,37.30)\end{array}$ \\
\hline $85+$ & $\begin{array}{l}-11.14 \\
(5.53)\end{array}$ & $\begin{array}{l}-14.18 \\
(7.19)\end{array}$ & $\begin{array}{c}1.08 \\
(5.27)\end{array}$ & $\begin{array}{c}5.62 \\
(7.06)\end{array}$ & $\begin{array}{c}-19.30,12.89 \\
(-32.68,26.27)\end{array}$ & $\begin{array}{c}-30.23,22.98 \\
(-47.14,39.89)\end{array}$ \\
\hline $\begin{array}{l}\text { Gender (“Male” } \\
\text { omitted) }\end{array}$ & & & & & & \\
\hline female & $\begin{array}{c}0.68 \\
(2.19)\end{array}$ & $\begin{array}{c}0.87 \\
(2.21)\end{array}$ & $\begin{array}{c}0.13 \\
(2.11)\end{array}$ & $\begin{array}{c}0.24 \\
(2.11)\end{array}$ & $\begin{array}{c}-9.13,10.87 \\
(-14.48,16.22)\end{array}$ & $\begin{array}{c}-8.99,11.01 \\
(-14.56,16.58)\end{array}$ \\
\hline $\begin{array}{l}\text { Race (“White” } \\
\text { omitted) }\end{array}$ & & & & & & \\
\hline black & $\begin{array}{l}-8.80 \\
(2.73)\end{array}$ & $\begin{array}{l}-9.24 \\
(2.74)\end{array}$ & $\begin{array}{l}-4.72 \\
(2.96)\end{array}$ & $\begin{array}{l}-4.88 \\
(2.95)\end{array}$ & $\begin{array}{c}-14.89,6.98 \\
(-20.73,12.83)\end{array}$ & $\begin{array}{c}-14.80,7.26 \\
(-20.89,13.35)\end{array}$ \\
\hline other & $\begin{array}{l}-4.49 \\
(3.99)\end{array}$ & $\begin{array}{l}-4.68 \\
(4.01)\end{array}$ & $\begin{array}{c}0.66 \\
(3.79)\end{array}$ & $\begin{array}{c}0.15 \\
(3.81)\end{array}$ & $\begin{array}{c}-14.27,7.64 \\
(-19.45,12.82)\end{array}$ & $\begin{array}{c}-14.74,10.55 \\
(-20.36,16.17)\end{array}$ \\
\hline $\begin{array}{l}\text { Education ("No } \\
\text { diploma” omitted) }\end{array}$ & & & & & & \\
\hline High school & $\begin{array}{l}10.96 \\
(3.06)\end{array}$ & $\begin{array}{l}11.98 \\
(3.17)\end{array}$ & $\begin{array}{l}-1.22 \\
(3.02)\end{array}$ & $\begin{array}{l}-1.24 \\
(3.02)\end{array}$ & $\begin{array}{c}-11.67,10.73 \\
(-17.34,16.40)\end{array}$ & $\begin{array}{c}-13.02,10.35 \\
(-18.77,16.11)\end{array}$ \\
\hline Some college & $\begin{array}{l}12.43 \\
(4.68)\end{array}$ & $\begin{array}{l}12.73 \\
(4.70)\end{array}$ & $\begin{array}{c}6.98 \\
(4.39)\end{array}$ & $\begin{array}{c}7.19 \\
(4.41)\end{array}$ & $\begin{array}{c}-8.09,17.96 \\
(-15.54,25.40)\end{array}$ & $\begin{array}{c}-10.08,18.15 \\
(-17.79,25.86)\end{array}$ \\
\hline Bachelor & $\begin{array}{c}7.99 \\
(3.91)\end{array}$ & $\begin{array}{c}9.07 \\
(4.02)\end{array}$ & $\begin{array}{c}6.27 \\
(3.77)\end{array}$ & $\begin{array}{c}6.18 \\
(3.79)\end{array}$ & $\begin{array}{c}-17.24,9.30 \\
(-26.61,18.68)\end{array}$ & $\begin{array}{c}-18.57,9.25 \\
(-27.43,18.12)\end{array}$ \\
\hline Graduate & $\begin{array}{c}2.50 \\
(4.56)\end{array}$ & $\begin{array}{c}3.28 \\
(4.61)\end{array}$ & $\begin{array}{l}-3.90 \\
(4.09)\end{array}$ & $\begin{array}{l}-3.34 \\
(4.11)\end{array}$ & $\begin{array}{c}-17.94,10.80 \\
(-28.66,21.53)\end{array}$ & $\begin{array}{c}-20.56,10.67 \\
(-31.39,21.50)\end{array}$ \\
\hline $\begin{array}{l}\text { Cognition score (Mid } \\
\text { tercile omitted) }\end{array}$ & & & & & & \\
\hline Bottom tercile & - & $\begin{array}{l}-3.99 \\
(4.93)\end{array}$ & - & $\begin{array}{c}2.79 \\
(4.90)\end{array}$ & - & $\begin{array}{c}-15.20,18.18 \\
(-25.54,28.53)\end{array}$ \\
\hline Top tercile & - & $\begin{array}{l}-3.45 \\
(2.88)\end{array}$ & - & $\begin{array}{l}-3.46 \\
(2.59)\end{array}$ & - & $\begin{array}{c}-7.71,14.16 \\
(-14.42,20.86)\end{array}$ \\
\hline Constant & $\begin{array}{l}21.53 \\
(3.69)\end{array}$ & $\begin{array}{l}24.76 \\
(6.21) \\
\end{array}$ & $\begin{array}{l}14.54 \\
(3.83) \\
\end{array}$ & $\begin{array}{l}11.72 \\
(6.09) \\
\end{array}$ & $\begin{array}{l}13.31,46.75 \\
(4.91,55.15) \\
\end{array}$ & $\begin{array}{c}4.36,53.98 \\
(-10.07,68.40) \\
\end{array}$ \\
\hline $\mathrm{N}$ & 591 & 591 & 431 & 431 & 431 & 431 \\
\hline
\end{tabular}

Note: Standard errors in parentheses. $\mathrm{N}=$ number of observations 